\title{
Forest plant and macrofungal differences in the Greater and Lesser Khingan Mountains in Northeast China: A regional-historical comparison and its implications
}

\author{
Yuanyuan Wang ${ }^{2,5} \cdot$ Hui Wen ${ }^{1}$ Kai Wang ${ }^{2,5}$. \\ Jingxue Sun ${ }^{1} \cdot J^{2}$ inghua $\mathbf{Y u}^{3}$ • Qinggui Wang ${ }^{4}$. \\ Wenjie Wang ${ }^{1,2}$
}

Received: 13 November 2020 / Accepted: 8 February 2021 / Published online: 21 April 2021

(C) The Author(s) 2021

\begin{abstract}
Forests in Northeast China in the Greater and Lesser Khingan Mountains (GKM and LKM) account for nearly $1 / 3$ of the total state-owned forests in the country. Regional and historical comparisons of forest plants and macrofungi will favor biological conservation, forest management and economic development. A total of 1067 sampling plots were surveyed on forest composition and structure, with a macrofungi survey at Liangshui and Huzhong Nature Reserves in the center of two regions. Regional and historical differences of these parameters were analyzed with a redundancy ordination of their complex associations. There were 61-76 families, 189-196 genera, and 369-384
\end{abstract}

Project funding: This work was supported by the National Natural Science Foundation of China (Grant No. 41730641); Project from Ministry of Science and Technology of China (Basic Research project: 2014FY110600 and 13-5 Project: 2016YFA0600802).

The online version is available at http://www.springerlink.com.

Corresponding editor: Yu Lei.

Yuanyuan Wang and Hui Wen contributed equally to this work.

Supplementary Information The online version contains supplementary material available at https://doi.org/10.1007/ s11676-021-01313-z.

Wenjie Wang

wjwang225@hotmail.com

1 Key Laboratory of Forest Plant Ecology (MOE), College of Chemistry, Chemical Engineering and Resource Utilization, Northeast Forestry University, Harbin 150040, People's Republic of China

2 Northeast Institute of Geography and Agroecology, Chinese Academy of Sciences, Changchun 130102, People's Republic of China species, which was only $1 / 3$ of the historical records. The same dominant species were larch and birch with Korean pine (a climax species) less as expected from past surveys in the LKM. Shrub and herb species were different in the two regions, as expected from historical records. There was $10-50 \%$ lower species diversity (except for herb evenness), but 1.8- to 4-time higher macrofungi diversity in the GKM. Compared with the LKM, both tree heights and macrofungi density were higher. Nevertheless, current heights averaging $10 \mathrm{~m}$ are half of historical records ( $>20 \mathrm{~m}$ in the 1960s). Edible macrofungi were the highest proportion in both regions, about twice that of other fungal groups, having important roles in the local economy. A major factor explaining plant diversity variations in both regions was herb cover, followed by shrubs in the GKM and herb-dominant species in the LKM. Factors responsible for macrofungi variations were tree density and shrub height. Vaccinium vitis-idaea and Larix gmelinii in the GKM but tree size and diversity were important factors in the LKM. Our findings highlighted large spatial and historical differences between the GKM and LKM in plant-macrofungal composition, forest structure, and their complex associations, which will favor precise conservation and management of forest resources in two region in the future.

3 Institute of Applied Ecology, Chinese Academy of Sciences, Shenyang 110016, People's Republic of China

4 Department of Agricultural Resources and Environment, Heilongjiang University, Harbin 150080 , People's Republic of China

5 University of Chinese Academy of Sciences, Beijing 100049, People's Republic of China 
Keywords Forest structure $\cdot$ Biodiversity $\cdot$ Redundancy ordination $\cdot$ Species dominance $\cdot$ Structure-speciesdiversity complex association decoupling

\section{Introduction}

Biodiversity is one of the most critical factors determining ecosystem functions and services in maintaining energy flow, purifying the environment, and regulating microclimate (Wang 2019; Yang et al. 2019). For plants, detailed records of species composition of trees, shrubs and herbs in sampling plots is fundamental for the study of diversity, evenness and richness, and the survey of community characteristics related to individual size and density is the basis for understanding the relationship between forest structure and ecosystem function (Wang et al. 2020a, b). There is less research on macrofungi compared to plants, and the classification of species and their functional types (edibility, medicinal and toxicity) is a major interest of numerous scholars (Mao 2000; Liu 2004; Bau and Li 2010; Deng 2010; Wu et al. 2019). China's forest resources are in a critical period of transition from insufficient quantities and low quality to a high quality and rapid accumulation (Qian 2014; Yang 2018). Comparison of the current status and historical records may help to identify steps to improve plant and fungal resources, their conservation, and management for enabling this transition.

Complex decoupling among species diversity, species dominance, forest structure and geo-climatic conditions is crucial for conservation and management practices, and inclusion of forest characteristics at different vertical layers, including taxonomic groups, plant size and density, will help the evaluation of forest resources. The dominance of species (importance value and abundance), species diversity (richness, Simpson and Shannon-Wiener index, evenness index), combined with forest characteristics are required for understanding diversity formation mechanisms (Song and Liu 1995; Ali et al. 2018). A statistical method such as redundancy analysis (RDA) is beneficial to find statistically significant factors responsible for biodiversity variations $(\mathrm{Gu}$ et al. 2020; Wang et al. 2020a, b).

Forests in the Greater and Lesser Khingan Mountains (GKM and LKM), covering approximately 0.4 million $\mathrm{km}^{2}$, are important state-owned forests and classified as priority areas of the Natural Forest Protection Program (NFPP), a program of forest protection first established in 2000. Several studies using relatively small numbers of sample plot $(<100)$ were on vegetation resources (Han et al. 2004; Xie 2017; Yang et al. 2017a; Sun et al. 2020), species diversity (Zhou et al. 1998; Mao and Zhu 2006; Zhang et al. 2007) and structure (Xu and Jin 2012; Ren et al. 2013; Yang 2019), concentrated mainly in a single protected area or region.
Large- scale integrated, comparative analysis of macrofungi and plant resources has not reported for the GKM and LKM. NFPP has currently banned timber harvesting, and rational utilization of understory plant and macrofungal resources has become a major income for millions of local people (Bau and Li 2010; Wang et al. 2012; Mysological-Societyof-China 2016; Wu et al. 2019). Detailed comparison of forest sources on plants and macrofungi, together with timberrelated data, is necessary for the implementation of forest policies according to regional differences during the second stage of NFPP (http://www.forestry.gov.cn/).

In this study, we hypothesized that sharp regional and historical differences in plant and macrofungal composition, and forest structure, as well as their different associations require different measures for biodiversity conservation and management in the GKM and LKM. We were particularly interested in exploring the following questions: (1) What are the differences between dominant species, community structure and species diversity of plants and macrofungi in the two regions and the differences between today and in the past; (2) What is the association between species diversity and abundance and forest structure; (3) What is the association between macrofungi diversity and abundance, forest structure, and plant species diversity.

\section{Materials and methods}

\section{Experimental design and plot census}

A total of 1067 plots (469 plots in the GKM, 598 in the LKM) were surveyed for tree, shrub and herb species. Plot sizes for the tree and macrofungi components were $30 \mathrm{~m} \times 30 \mathrm{~m}$. In each plot, ten $2 \mathrm{~m} \times 2 \mathrm{~m}$ shrub subplots and ten $1 \mathrm{~m} \times 1 \mathrm{~m}$ herb subplots were established. Elevation, latitude and longitude were recorded for each plot. (Fig. 1, Table 1). Species names, size of tree, shrub and herb layers, plant density (number, cover) and individual heights and diameters were recorded. Altitude, slope aspect (sunny, shade and partial sunshade), position (upper, middle, bottom or flat), and gradient in degrees were recorded.

A total of 146 plots for macrofungi were surveyed in Liangshui (center of the LKM) and Huzhong (center of the GKM) in the National Nature Reserves. In each $30 \mathrm{~m} \times 30 \mathrm{~m}$ plot, species name, the total number of each macrofungi, and growing habitats (soil, litter, living tree and deadwood) were recorded three times by cross-line checking. Macrofungi were identified by traditional phenology with the help of microscopic observation. For phenological observation, visual identification or the use of magnifying lens were used to check e color, shape, ancillary features of the hypophysial, pileus, mediotrastum, collarium, stipe, volva and rhizomorph on-site and also 


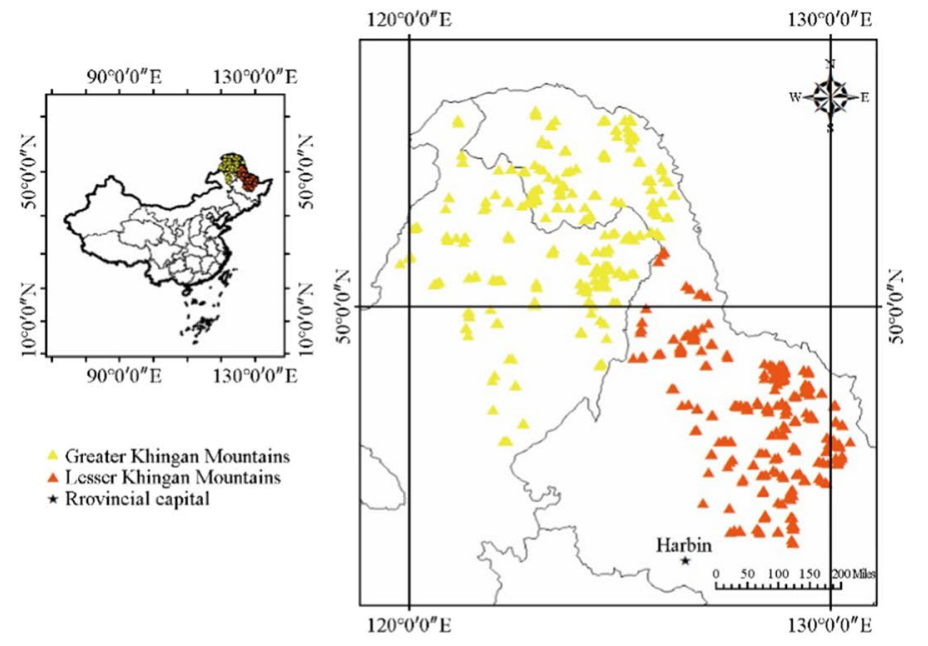

(a)

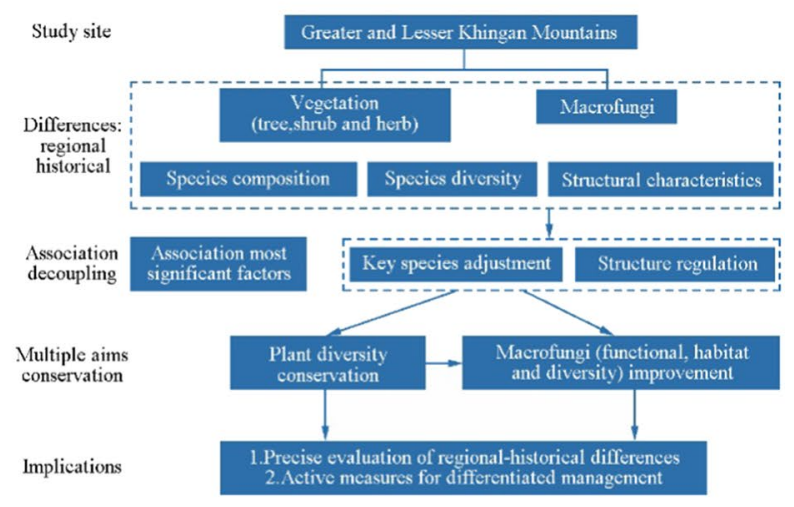

(b)

Fig. 1 a Geographical location of sampling plots, yellow and orange triangles plots in the GKM and LKM, respectively, and b the technical route of this study

Table 1 Differences of two regions of the GKM and LKM in geoclimatic and topographical conditions

\begin{tabular}{|c|c|c|c|c|c|c|}
\hline & Geographical coordinates & Elevation $(\mathrm{m})$ & $\operatorname{MAT}\left({ }^{\circ} \mathrm{C}\right)$ & $\mathrm{MAP}(\mathrm{mm})$ & Climate type & Soil type \\
\hline GKM & $\begin{array}{l}121^{\circ} 40^{\prime}-127^{\circ} 10^{\prime} \mathrm{E} \\
50^{\circ} 05^{\prime}-53^{\circ} 34^{\prime} \mathrm{N}\end{array}$ & $1200-1300$ & -6 to 1 & $240-442$ & $\begin{array}{l}\text { Continental mon- } \\
\text { soon climate in } \\
\text { Cold temperate } \\
\text { zone }\end{array}$ & $\begin{array}{l}\text { Brown coniferous forest soil, meadow soil, } \\
\text { marsh soil and gray forest soil }\end{array}$ \\
\hline LKM & $\begin{array}{l}125^{\circ} 54^{\prime}-130^{\circ} 56^{\prime} \mathrm{E} \\
46^{\circ} 10^{\prime}-51^{\circ} 02^{\prime} \mathrm{N}\end{array}$ & $500-1000$ & -1 to 1 & $550-700$ & $\begin{array}{l}\text { Continental mon- } \\
\text { soon climate in } \\
\text { the North temper- } \\
\text { ate zone }\end{array}$ & Dark brown soil, meadow soil and marsh soil \\
\hline
\end{tabular}

Mean annual temperature (MAT), mean annual precipitation (MAP); GKM information from (Fu et al. 2016), LKM was from (Liu 2012; Tobner et al. 2016)

a minimum of five digital photos were taken for later rechecks. For some macrofungi, spore prints from the sporocarp were also collected; Melzer's reagent was used to identify fungi through amyloid (from blue to black) and dextrinoid (brown to red-brown) color reaction. All photos were taken from different angles and simple anatomy, named according to sample number for convenient later laboratory recognition. The identification in the field and in the laboratory was carried out by referring to relevant literature (Huang 1998; Mao 2000; Liu 2004; Xiang 2005; Yu et al. 2005; Chen et al. 2013; Nature-Museum-Editorial-Board 2014; Shao and Xiang 2017). A re-confirmation of identification was also achieved with the assistance of a noted macrofungi expert, Prof. Cunti Xiang, retired from NEFU with two macrofungal books (Shao and Xiang 1997; Xiang 2005). The macrofungi were also checked in the 10th edition of the fungus dictionary (Kirk et al. 2008), the IndexFungorum online database (www.index fungorum.org and www.speciesfungorum.org).

\section{Dominant species abundance and diversity}

Dominance at different taxonomic levels was recognized by the importance value (IV) as an average of relative coverage, frequency and abundance. Relative abundance was calculated by the individual number of species divided by the total individual number in the plot. According to the IV, the top five species, genera, and families in the tree, shrub and herb layers were recognized as dominant in the two regions. The calculations of IV are listed as Eqs. 1-4 in Table 2. After identification of dominance, the relative abundance in species, genera and families in each plot were also compared to find differences in vegetation in the GKM and LKM.

Four indices of species diversity were calculated from the field data as richness, Shannon-Wiener and Simpson diversity and evenness (Eqs. 5-8, Table 2), which have been used widely in previous reports (Ma et al. 1995). Plant species names were confirmed from the Flora of China (http://www. iplant.cn/frps), the Chinese Field Herbarium (CFH, http:// 
Table 2 Calculation of species composition and diversity traits and structural parameters

\begin{tabular}{|c|c|c|c|c|}
\hline Index & Formula & & & Explanation \\
\hline \multirow[t]{4}{*}{ Species } & Important value (IV) & $\mathrm{IV}=(\mathrm{g}+\mathrm{m}+\mathrm{p}) / 3$ & (1) & \\
\hline & Relative coverage (g) & $\begin{array}{l}g=\text { The coverage of a species/Total } \\
\text { coverage of all species } \times 100 \%\end{array}$ & (2) & \\
\hline & Relative frequency (p) & $\begin{array}{l}p=\text { The frequency of a species/Total } \\
\text { frequency of all species } \times 100 \%\end{array}$ & (3) & \\
\hline & Relative abundance (m) & $\begin{array}{c}m=\text { The amount of a species/Total } \\
\text { amount of all species } \times 100 \%\end{array}$ & (4) & \\
\hline \multirow[t]{4}{*}{ Species diversity } & Richness index (R) & $R=S$ & (5) & $\begin{array}{l}P i \text { is the proportion of number of species } \\
i \text { to total number of the species; } S \text { is the } \\
\text { total of species } i \text { in the plot }\end{array}$ \\
\hline & Shannon-Wiener $(\mathrm{H})$ & $H=-\sum P i \ln P i$ & (6) & \\
\hline & Simpson index (D) & $D=1-\sum P i^{2}$ & (7) & \\
\hline & Evenness index (Jsw) & $J_{s w}=\left(-\sum \mathrm{Pi} \ln \mathrm{Pi}\right) \ln S$ & (8) & \\
\hline \multirow[t]{4}{*}{ Structural features } & Diameters at breast height $(\overline{\mathrm{DBH}})$ & $\overline{\mathrm{DBH}}=\frac{\left(\sum_{i=1}^{m} \sum_{j=1}^{n} D_{i j}\right)}{\sum_{n=1}^{m} n}$ & (9) & $\begin{array}{l}\text { where, } D i j \text { and } H i j \text { are the DBH and } \\
\text { height of the } j_{\text {th }} \text { tree in the } i_{\text {th }} \text { species; } \\
m \text { is total species number; } n \text { is the } \\
\text { measured tree for each species, } C i \text { is } \\
\text { the coverage of the } i_{\text {th }} \text { species and } A \text { the } \\
\text { area of the plot }\end{array}$ \\
\hline & Mean height $(\bar{H})$ & $\bar{H}=\frac{\sum_{i=1}^{m} \sum_{j=1}^{n} H_{i j}}{\sum_{n=1}^{m} n}$ & (10) & \\
\hline & Mean density $(\bar{D})$ & $\bar{D}=\left(\sum_{\mathrm{i}=1}^{\mathrm{m}} \mathrm{n}\right) / \mathrm{A}$ & (11) & \\
\hline & Mean coverage $(\overline{\mathrm{C}})$ & $\bar{C}=\frac{\left(\sum_{i=1}^{m} c_{1}+c_{2}+\ldots+c_{i}\right)}{m}$ & (12) & \\
\hline
\end{tabular}

www.cfh.ac.cn/spdb/spsearch.aspx), and the Flora of Woody Plants and Herbs in Northeast China (Liu 1955; Fu 2004). At the first appearance of Latin names of plant species, the authority names were listed; while thereafter, abbreviated names with genus and given name were used for simplifying the description of the result.

\section{Forest structure}

In each plot, all trees $>2 \mathrm{~cm}$ in basal diameter were measured: for trees, diameter at breast height (DBH), height (Th), and density (Td); for shrubs, density ( $\mathrm{Sd}$ ), height (Sh) and cover (Sc), and for herbs, cover of each species (Hc) and height (Hh). Shrubs and herb cover were determined as the percentage of area covered by the species to the total area. Tree and shrub densities were calculated as the number of individuals divided by the plot area. All these structural parameters were averaged as a plot mean value. Equations are listed in Table 2.

\section{Macrofungi traits}

After species identification, all macrofungi were divided into five utilization-related functional groups: edible, medicinal, toxic, wood-rot, as well as an unknown function, and four habitat-related functional groups (living tree, deadwood, soil-based, and litter habitat). These function groups were used to analyze the functional changes of macrofungi from habitat and utilization viewpoints (macrofungi names in Table S1).

The diversity of macrofungi was calculated following (Bau and Li 2000).

Comprehensive index $(P i)=1 / 3\left(A_{i}+B_{i}+C_{i}\right)$

Macrofungi Margalef richness index $(\mathrm{MR})=\frac{S-1}{\operatorname{Ln}(\mathrm{N})}$

Macrofungi Shannon - wiener index $\left(\mathrm{MH}^{\prime}\right)=-\sum P_{i} \ln P_{i}$

Macrofungi Simpson index $(\mathrm{MD})=1-\sum P_{i}^{2}$

Macrofungi Pielou evenness index $(\mathrm{ME})=\left(-\sum P_{i} \ln P_{i}\right) / \ln S$

where $A_{\mathrm{i}}, B_{\mathrm{i}}, C_{\mathrm{i}}$ are relative densities (species $i$ density/total density of the plot), relative abundance (species $i$ number/ total macrofungi number in the plot) and relative frequency 
(species $i$ frequency in total surveyed plots/the number of plots). $S$ and $N$ are the total number of species and macrofungi numbers in the $i_{\text {th }}$ plot.

To determine compositional changes, the appearances of different taxon (total sum and plot average), and their relative abundance were computed. The relative abundance of different taxon in different regions were calculated as the percentage of dominant species, genera, family and order to total macrofungi observations in this study.

\section{Data processing}

A one-way analysis of variance (ANOVA) by SPSS 22.0 (SPSS, USA) was used to compare the significance of the two regional differences of dominant families, genera and species, structural features and species diversity of plants and macrofungi, and different functions (edible, medicinal, toxic, wood-rot, and unknown function macrofungi) and habitat (living tree, deadwood, soil-based and litter-habitat macrofungi). To find the relative change, a GKM/LKM ratio was calculated for all parameters. A statistically significant larger ratio indicated either that large regional differences existed or there were no differences.

Redundancy analysis (RDA) was carried out to explore the effect of species abundance and structural characteristics on diversity and the coupling relationship of macrofungi (different habitats, functional groups and diversity indices), forest characteristics (dominant species abundance and structural features of tree, shrub and herb layers) in the two regions. A comparison with detrended correspondence analysis (DCA) is listed in Table S2. Significant factors responsible for plant species diversity and macrofungi variations were identified under simple term and conditional term effects (excluding multicollinearity among factors). RDA analysis was performed by Canoco 5 (Biometrics Ltd., Plant Research International, the Netherland).

\section{Results}

\section{Differences in the composition of plant resources}

The number of families, genera and species in both regions were similar, 61 families, 189 genera and 384 species of plants in the GKM, among them, 8 families, 17 genera and 29 species were in the tree layer, 12 families, 20 genera and 41 species in the shrub layer, and 49 families, 159 genera, 314 species in the herb layer. There were 76 families, 196 genera and 369 species in the LKM, including 12 families, 21 genera and 45 species in the canopy layer, 18 families, 26 genera and 42 species in the shrub layer, and 60 families, 153 genera and 282 species in the herb layer (Tables S3 and S4).
Importance value (IV)-based relative abundance data showed that dominant families, genera and species of trees, shrubs and herbs were different in the GKM and LKM, especially for herbs and shrubs. The top four tree families, Pinaceae, Betulaceae, Salicaceae and Fagaceae, were the same in both regions, accounting for $98.9 \%$ of IV in the GKM and $82.8 \%$ in the LKM (Fig. 2a and b). The dominant genera of the two regions, Larix, Betula, Populus, Pinus, and Quercus were identical and accounting for $95.6 \%$ in the GKM and $74.6 \%$ in the LKM (Fig. 2c and d). Dominant tree species in the GKM included Larix gmelinii (Ruprecht) Kuzeneva, Betula platyphylla Suk, Populus davidiana Dode, Quercus mongolica Fischer ex Ledebour and Pinus sylvestris var. mongolica Litv. (91.1\% of total IV), with the first four were the same, followed by Pinus koraiensis Siebold et Zuccarini in the LKM (Fig. 2e and f).

The most abundant shrub family in the GKM was Ericaceae ( $41.7 \%$ of IV, $2.3 \%$ in LKM), followed by Rosaceae and Betulaceae (the dominant top two in the LKM) (Fig. 3a and b). The dominant shrub genera in the GKM were Vaccinium, Spiraea, Corylus, Rhododendron and Betula $(70.5 \%$ of IV sum). Corylus and Spiraea were also found in the LKM (58.3\% of IV), followed by Sorbaria, Rosa and Lonicera (6.5-8.0\% of IV) (Fig. 3c and d). The dominant shrub species were Vaccinium vitis-idaea Linn, Corylus heterophylla Fisch. ex Trautv, Rhododendron dauricum Linn, Spiraea media Schmidt. and Ledum palustre L. (54.9\% of IV) in the GKM. In the LKM, the two most abundant species were Spiraea salicifolia L. and Corylus mandshurica Maxim. (48.4\% of IV), followed by Corylus heterophylla, Sorbaria sorbifolia (L.) A. Br. and Rosa davurica Pall. (each IV was nearly $8.0 \%$ ) (Fig. 3e and f).

The dominant herb families in the GKM were Cyperaceae, Poaceae, Rosaceae, Asteraceae and Asparagaceae (58.7\% of IV), but the ranking was different in the LKM (Fig. 4a and b). Dominant herb genera in the GKM were Carex, Deyeuxia, Sanguisorba, Vicia and Pyrola (nearly half of the IV), the first two in the GKM along with Caldesia, Filipendula and Equisetum played an important role in the LKM (Fig. 4c and d). Dominant herb species in the GKM included Deyeuxia purpurea (Trinius) Kunth, Carex callitrichos V. Krecz, Sanguisorba officinalis L., Pyrola rotundifolia Linn. and Fragaria orientalis Lozinsk. (30.9\% of IV); only the first principal species was the same, followed by Caldesia parnassifolia (Bassi ex L.) Par, Filipendula palmate (Pall.) Maxim, Carex dispalata Boott and Equisetum sylvaticum $\mathrm{L}$. in the LKM (Fig. 4e and f).

The difference in species abundance showed that, in the tree layer, Larix gmelini, and Betula platyphylla had the largest proportions in both regions. Larix gmelini in the GKM was twice that in the LKM $(p<0.01)$. The abundance of Salicaceae (Populus and Populus davidiana) and Rosaceae $(p<0.01)$ was $1.3-2.1$ times higher in the GKM, 
Fig. 2 Differences in the relative abundance in IV of tree families, genera and species in the two regions. Notes Relative abundance was based on the proportion of importance value (IV) for each species, genus, and family; names of the top five species in relative abundance in IV are highlighted in the pie chart and total ranks listed in Tables S3 and S4; relative abundance of each parameter $=$ IV of the parameter/total IV sum of all parameters in this layer

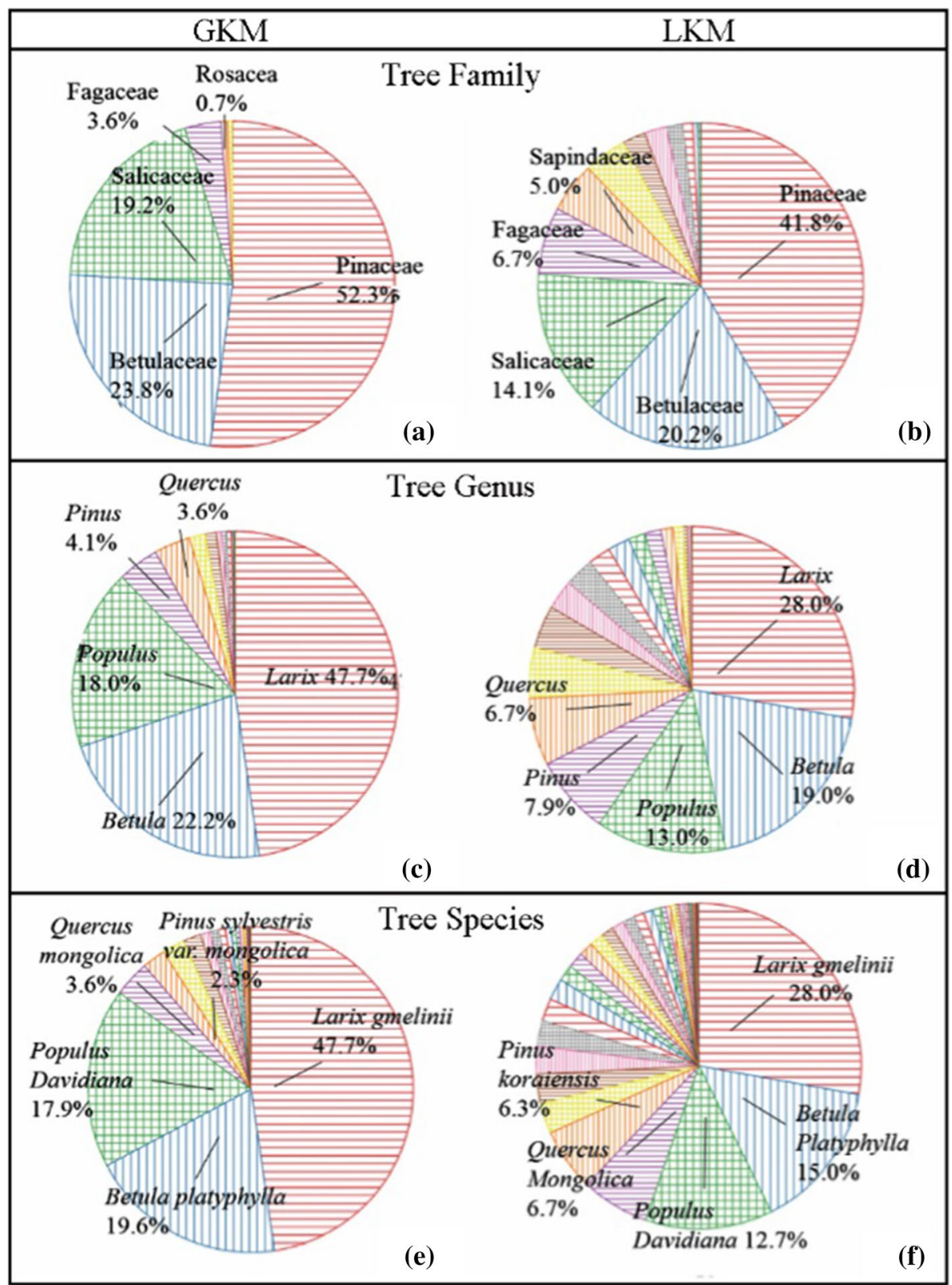

while Fagaceae (Quercus mongolica) in the GKM was half that of the LKM; Pinus koraiensis was only found in the LKM ( $p<0.01$, Fig. 5).

Compared with the LKM, the abundance of some shrub species was significantly higher in the GKM than in the LKM, such as Ericaceae - Vaccinium and Vaccinium vitis-idaea increased as much as 12-fold over the LKM; 13 times higher of Fabaceae, almost 2-10 times higher of Rhododendron (Rhododendron dauricum) and Ledum palustre in the GKM. In contrast, Betulaceae and Corylus were half of the LKM. The number of Spiraea salicifolia, Rosa davurica, Sorbaria sorbifolia and Corylus mandshurica were $1 / 10$ to half of the numbers in the LKM. The abundance of Caprifoliaceae and Lonicera in the LKM was much more than in the GKM (Fig. 6).

Herb families, genera and species such as Rosaceae, Sanguisorba and Sanguisorba officinalis, as well as Fragaria orientalis in the GKM were 3.4-5.1 times higher than in the LKM. Pyrola and Pyrola rotundifolia were 6.3-fold higher but Filipendula and Filipendula palmata were only 1/5-1/3 in the LKM. Fewer Carex dispalata and Alismataceae, Caldesia, Caldesia parnassifolia were also present in the LKM (Fig. 7). 
Fig. 3 Differences in the relative abundance in IV of shrub families, genera and species in the two regions

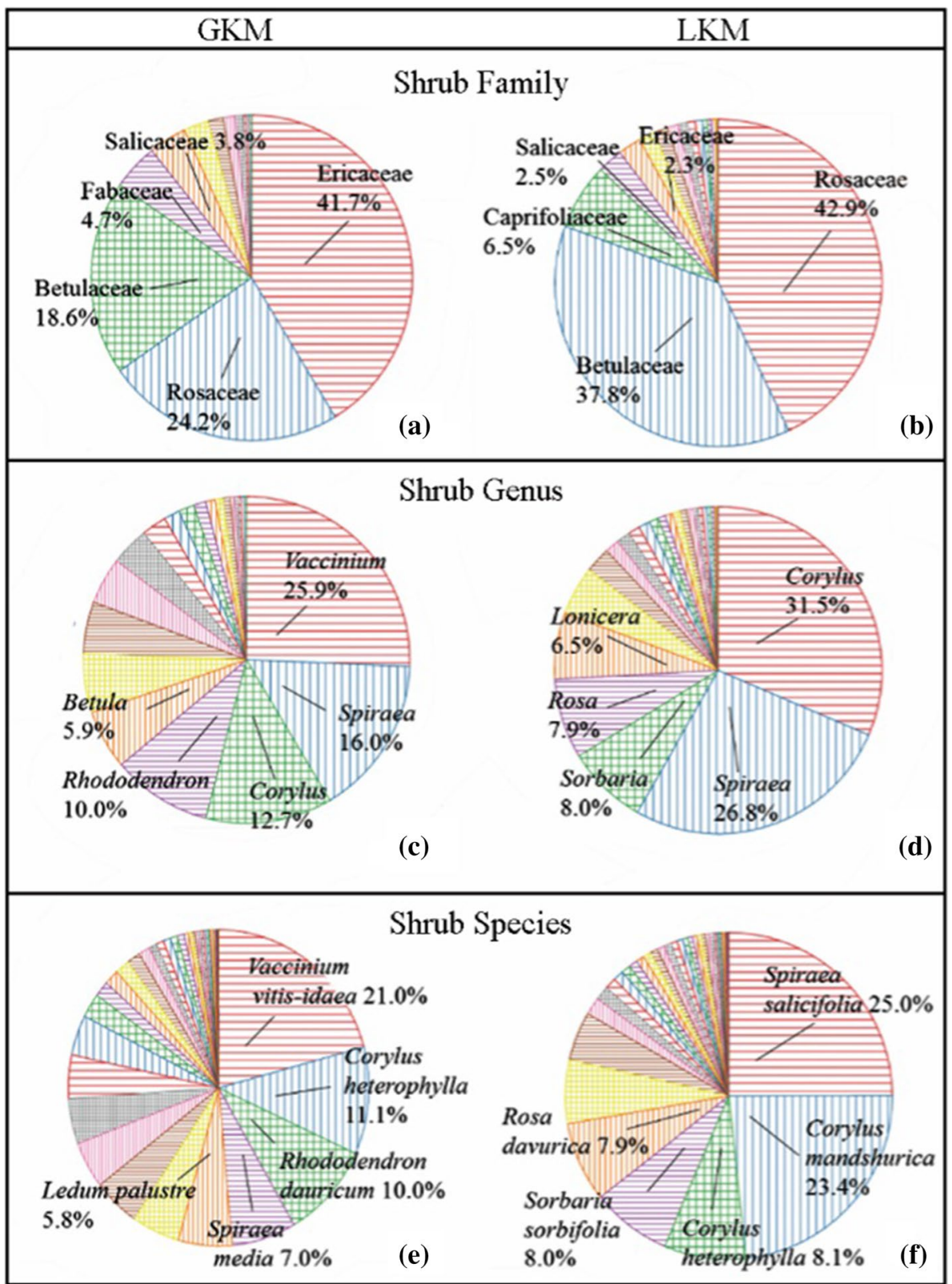

\section{Differences in the composition of macrofungi}

A total of 207 macrofungi spp. belonging to 24 families and 7 orders were found in the GKM with 141 species of 32 families and 10 orders in the LKM (Table S3 and S4).

The order Agaricales had the largest percentage of macrofungi in the two regions but was more abundant in the GKM compared to the LKM (56.5\% vs $40.0 \%)$. The most abundant family was Tricholomataceae in both regions (22.9-23.2\%), followed by Russulaceae in the GKM (14.8\%) and Polyporaceae in the LKM (18.8\%). The major species in the GKM were Cortinarius tenuipes, Xeromphalina campanell, Cortinarius croceofolius, Coriolus hirsutus and Xerocomus badius; Fomes fomentarius and Collybia acervata were relatively abundant (4\%) in the LKM (Fig. 8).

From the perspective of the functional groups in the two regions, edible macrofungi accounted for the largest proportion (2-22 times higher than other groups), followed by medicinal macrofungi (1.5-10 times higher). The abundance of all functional groups in the GKM was higher than in the LKM, 2-4 times higher of toxic, edible and wood-rod macrofungi in the GKM, but medicinal macrofungi were similar in the two regions. From the statistics of habitat, soilbased macrofungi accounted for the largest proportion in the GKM (5-21 times higher). The two-region comparison showed a higher abundance of different habitat fungi in the 
Fig. 4 Differences in the relative abundance in IV (importance value) of herb families, genera and species in the two regions

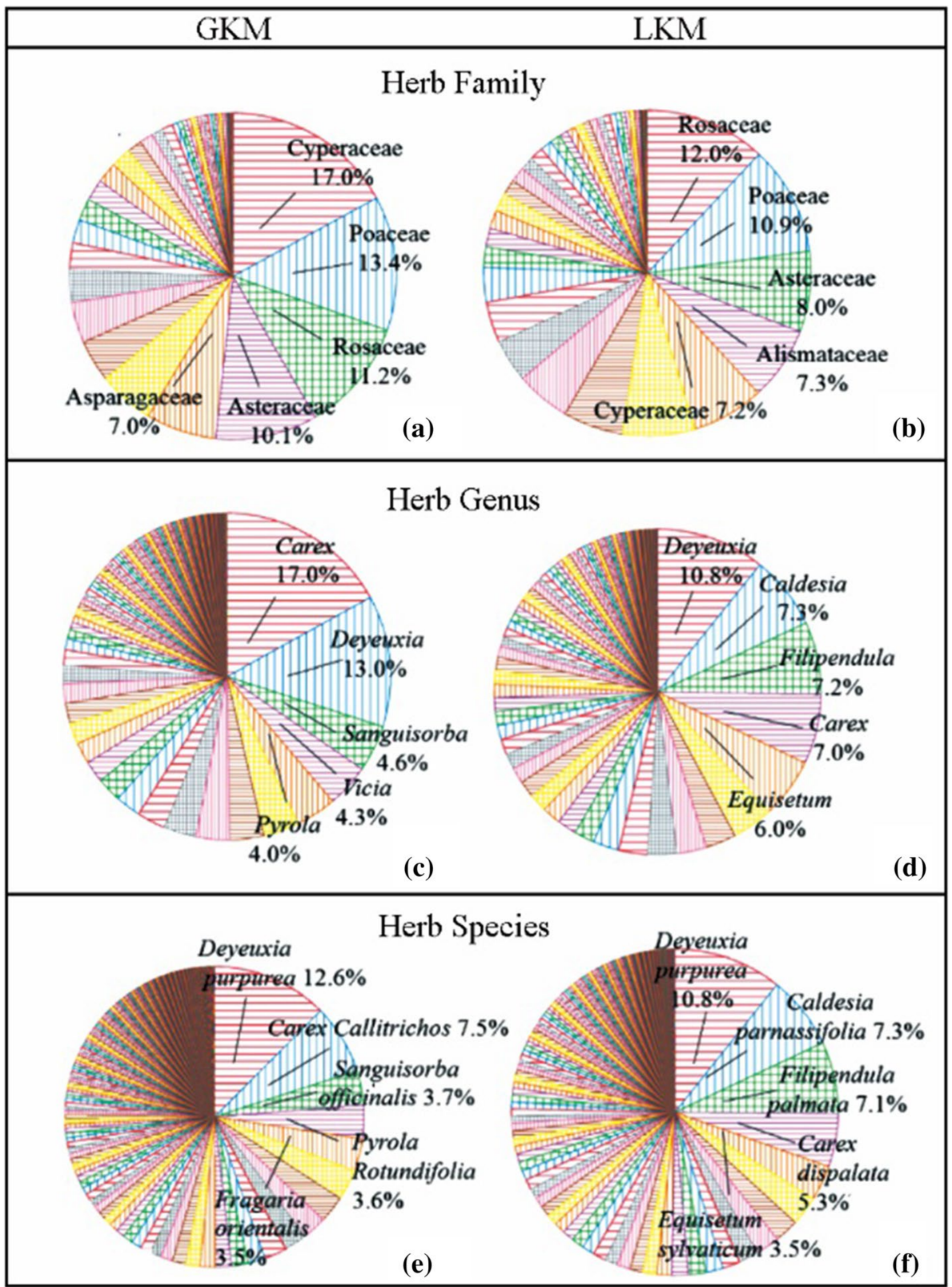

GKM, especially soil-based and deadwood macrofungi were $1.7-8.5$ times higher than in the LKM $(p<0.05$, Table 3$)$.

\section{Differences in plant and macrofungi communities}

Forest community characteristics in the two regions were significantly different $(p<0.05)$, and the average change was macrofungi $>$ shrub $>$ herb $>$ tree. There were denser forests (1.3 times higher in tree density, 8.2 times higher in shrub density, 2.1 times higher in herb coverage and 3.3 times higher in macrofungi density); smaller trees (heights and DBH reduced 10-20\%), smaller shrubs (height and cover reduced $60 \%$ ) and shorter herbs (height decreased by $40 \%$ ) in the GKM compared with those in the LKM (Table 4).

\section{Differences in plant and macrofungi species diversity}

Species diversity in the two regions was significantly different ( $p<0.05$ except for the Shannon-Wiener index and macrofungi evenness), and there was a larger change in macrofungi than for the vegetation. Compared with the LKM, macrofungi richness and diversity were 1.8-4 times higher but tree diversity, richness and evenness were 10-50\% lower in the GKM. Shrub richness was similar in the two regions; other shrub indices decreased $40 \%$ in the GKM, while herb richness decreased $30 \%$ but was distributed more evenly in the GKM (1.2 times higher of evenness, Table 4). 
Fig. 5 Comparison of individual abundance changes of dominant tree species, genera and families in the two regions; numbers above the bar indicate relative change between the two regions; significant differences in bold with $* *$ indicating $p<0.01$ and $* p<0.05$; The same as Figs. 6 and 7
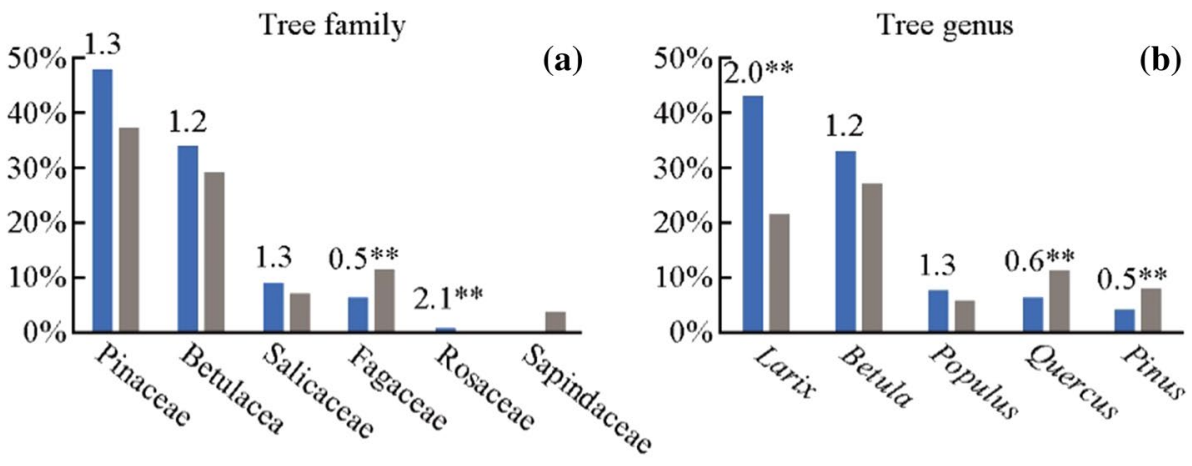

(b)

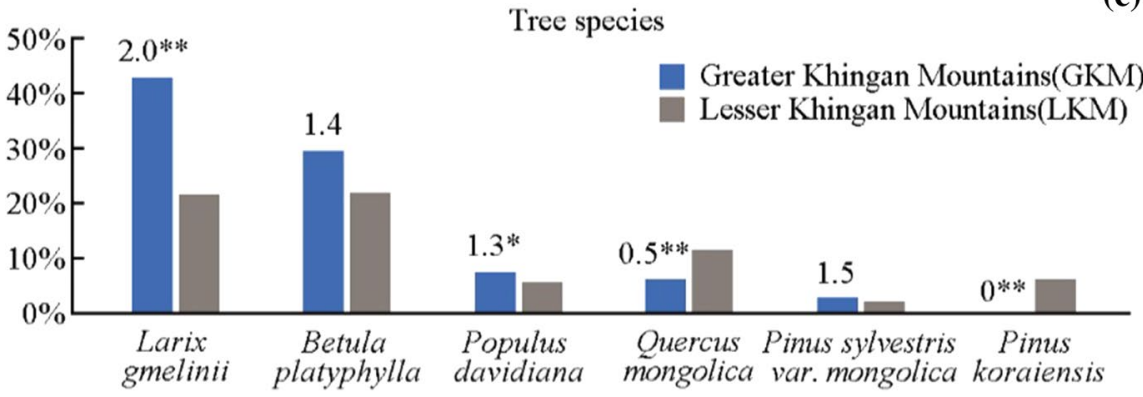

Fig. 6 Comparison of individual abundance changes of dominant shrub species, genera, and families in the two regions; NA, not available
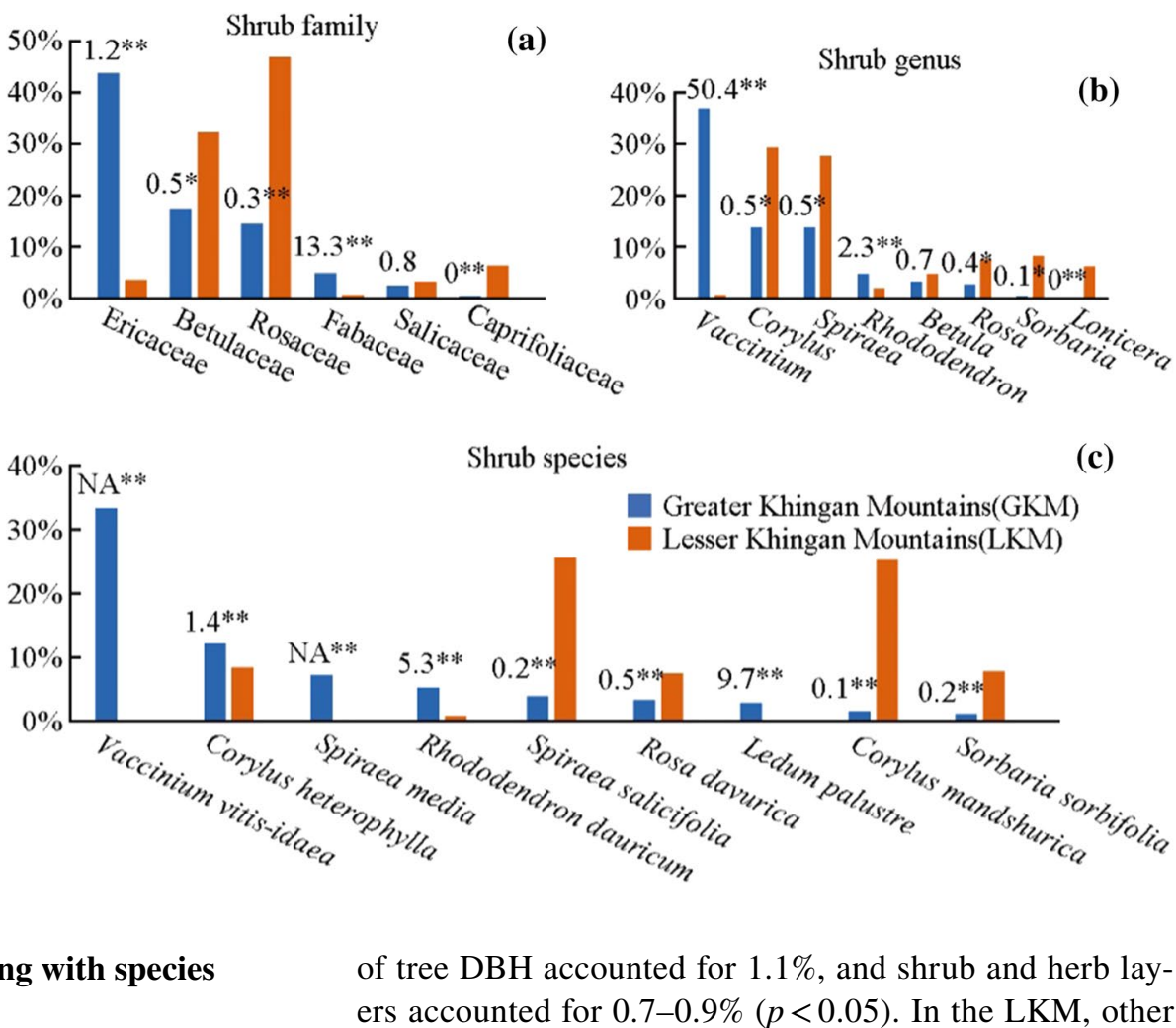

\section{abundance and forest structure}

Plant diversity association decoupling with species

Species diversity variations were similar (47.6\% in the GKM and $50.8 \%$ in the LKM), and the most significant parameter was the same as for herb cover in both regions. In the GKM, herb cover was $22.7 \%$, over twice as high as in the LKM (10\%). Other factors were key species abundance of shrubs, trees $(2-5 \%)$ and herbs (around 1\%), structural features of tree DBH accounted for $1.1 \%$, and shrub and herb layers accounted for $0.7-0.9 \%(p<0.05)$. In the LKM, other important factors included the abundance of herbs, shrubs and trees $(0.8-6.4 \%)$, and plant height and forest density $(0.6-2.1 \%)(p<0.05$, Table 5).

In the GKM, the increase in species diversity of trees, shrubs and herbs coincided with the reduction of herb cover and shrub density, and increasing shrub cover and herb height. Larger trees, together with more abundant Quercus 
Fig. 7 Comparison of individual abundance changes of dominant herb species, genera and families in the two regions; $\mathrm{NA}$, not available
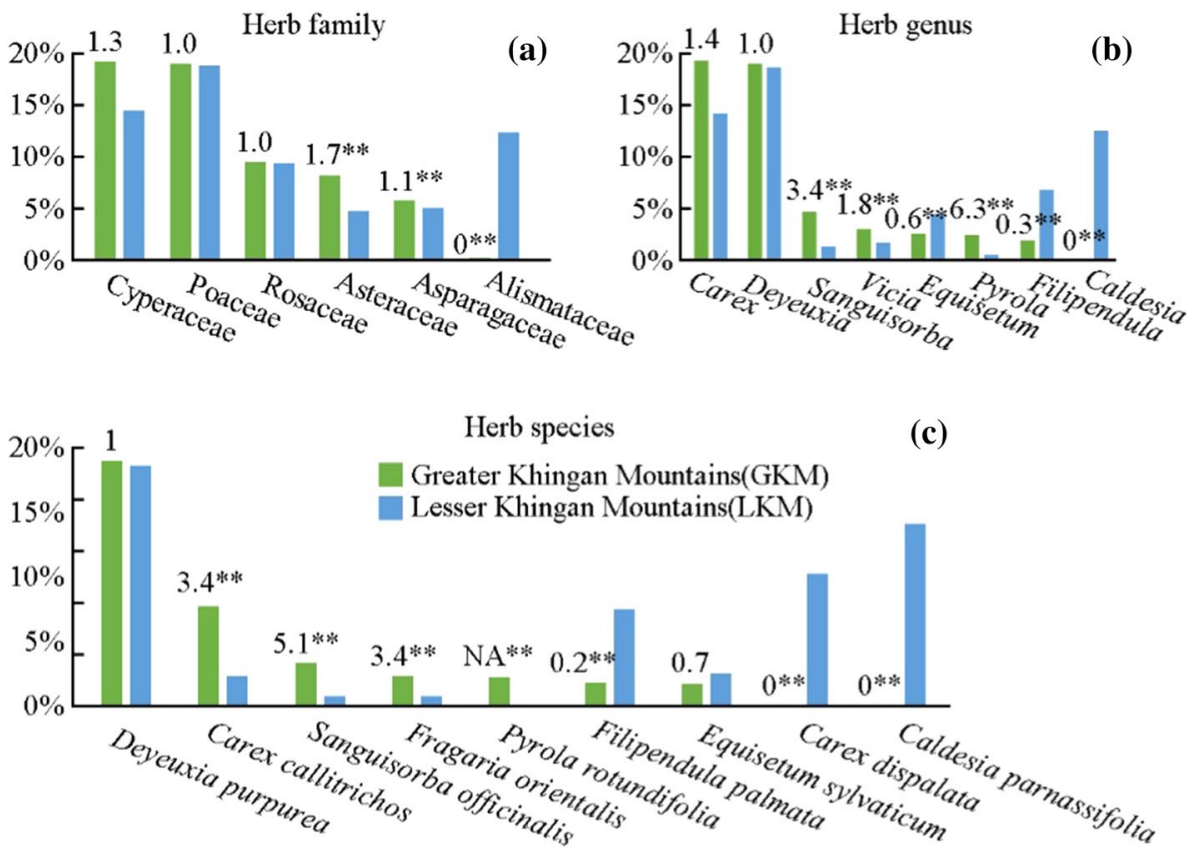

Herb species

(c)

Greater Khingan Mountains(GKM)

Lesser Khingan Mountains(LKM)

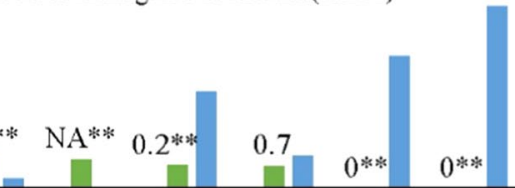

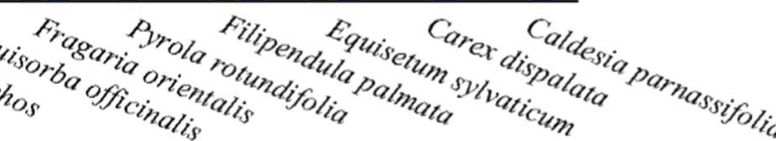

mongolica and Corylus heterophylla are usually accompanied by higher tree-herb diversity, while more Fragaria orientalis and less Vaccinium vitis-idaea and Deyeuxia purpurea reflected the higher shrub-herb diversity. In the LKM, shorter herbs, and less abundance of Deyeuxia purpurea, Caldesia parnassifolia, Larix gmelinii, Betula platyphylla and Spiraea salicifolia aligned with the higher diversity of all species. In addition, communities with lower herb cover, denser shrubs, and greater abundance of Corylus mandshurica, Quercus mongolica, Corylus heterophylla, Populus davidiana and Filipendula palmata had higher tree-herb diversity. In addition, shrub diversity increased with tree height and density (Fig. 9, Table 5).

Herb cover played the most important role in the increase in tree-herb diversity in the two regions. However, increased herb cover in the GKM was accompanied with the decrease of most of diversity indices; while in the LKM, Simpson, Shannon-wiener and evenness indices of shrubs increased with higher herb cover. In the GKM, shrub (10.2\%) contributed 2-5 times more than tree and herb species for diversity variations (2-5.2\%), while in the LKM, herb species were more common $(15.2 \%)$ than tree and shrub species (total 9.2-9.5\%). Less shrub density and higher herb heights led to higher species diversity in the GKM, but there was a lower tree-herb diversity in the LKM.

\section{Macrofungi-related association decoupling with plant species and structural factors}

The explanation for the effect on macrofungi variations were $56.2 \%$ and $44.5 \%$ in the GKM and LKM, respectively. Compared with the LKM, where only tree DBH and shrub species were significant factors, much more significant parameters were found in the GKM (Table 6).

In the GKM, macrofungi diversity and edible, soil-based macrofungi increased with more Vaccinium vitis-idaea and Larix gmelini and higher shrub cover, while macrofungi richness, medicinal, and wood rot macrofungi, living tree, deadwood and litter-based macrofungi increased with more abundant Spiraea media, higher shrub and herb cover and richness. All macrofungi of multiple functions, habitats and higher diversity increased with denser tree cover. In the LKM, the larger tree DBH and higher diversity but less Sorbaria sorbifolia led to more macrofungi of multiple function and habitat and higher diversity (Fig. 10, Table 6).

\section{Discussion}

\section{Forest quality in two regions: present and historical differences}

At the present time, the composition of the dominant tree species is similar in the two regions, but historically there were much greater differences (Table 7). At present, among the five dominant species in each region, four were the same historically in the canopy: Larix gmelinii, Betula platyphylla, Populus davidiana, and Quercus mongolica. However, of the top five shrub and herb species, only the shrub Corylus heterophylla and the herb Deyeuxia purpurea were the same in the two regions (Figs. 2, 3, 4). However, historically, Larix was dominant in the GKM and Pinus koraiensis broadleaf mixed forest was dominant climax vegetation in the LKM (Table 7). Due to extensive deforestation and poor 
Fig. 8 Proportion of macrofungi abundance in order, family and species in the GKM and LKM; names of the dominant species are highlighted, the rank listed in Tables S3 and S4; percentage of the species $=$ the abundance of the species/total abundance of all species
Table 3 Comparison of abundance changes of macrofungi in two regions

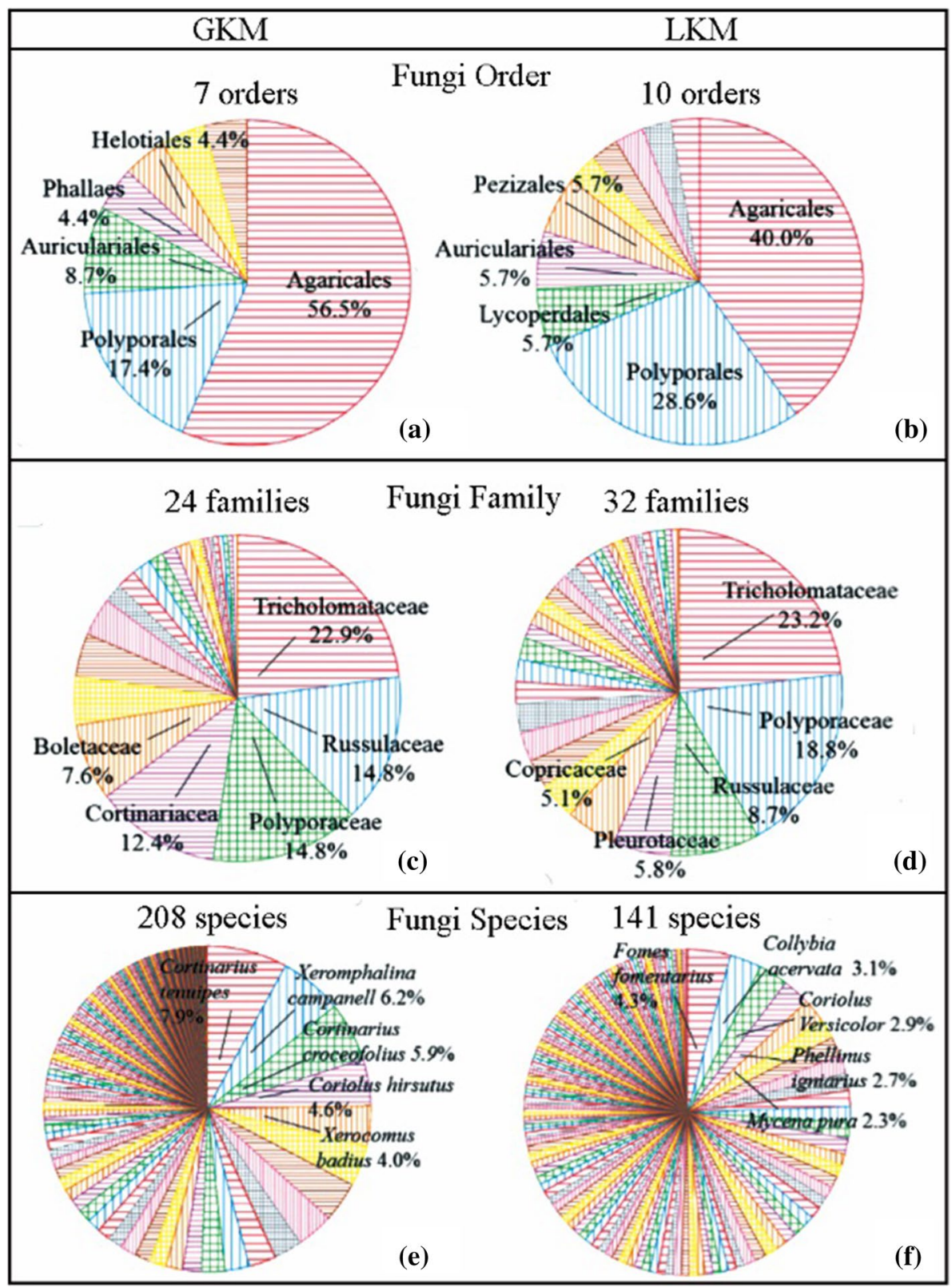

\begin{tabular}{llrrrl}
\hline Category & Type & GKM & LKM & $P$ value & $\begin{array}{l}\text { Relative change } \\
\text { (GKM/LKM) }\end{array}$ \\
\hline Utilization group & Edible macrofungi & $\mathbf{9 . 1 8}$ & $\mathbf{3 . 7 6}$ & $<\mathbf{0 . 0 1}$ & $\mathbf{2 . 4}$ \\
& Medicinal macrofungi & 2.52 & 1.8 & 0.18 & 1.4 \\
& Unknown function macrofungi & $\mathbf{1 . 6 3}$ & $\mathbf{0 . 1 7}$ & $<\mathbf{0 . 0 1}$ & $\mathbf{9 . 6}$ \\
& Toxic macrofungi & $\mathbf{1 . 0 7}$ & $\mathbf{0 . 2 8}$ & $<\mathbf{0 . 0 1}$ & $\mathbf{3 . 8}$ \\
& Woodrot macrofungi & $\mathbf{0 . 7 4}$ & $\mathbf{0 . 3 2}$ & $<\mathbf{0 . 0 1}$ & $\mathbf{2 . 3}$ \\
Habitat group & $\mathbf{1 1 . 7 8}$ & $\mathbf{1 . 3 9}$ & $<\mathbf{0 . 0 1}$ & $\mathbf{8 . 5}$ \\
& Soil-based macrofungi & $\mathbf{2 . 3 6}$ & $\mathbf{1 . 4 1}$ & $<\mathbf{0 . 0 1}$ & $\mathbf{1 . 7}$ \\
& Deadwood macrofungi & 1.27 & 1.66 & 0.17 & 0.8 \\
& Living tree macrofungi & 0.56 & 0.42 & 0.08 & 1.3 \\
\hline
\end{tabular}

Parameters in bold are significant elements $(p<0.05)$; the unit is individual 
Table 4 Comparison of plant structure and diversity of tree, shrub and herb components in two regions

\begin{tabular}{|c|c|c|c|c|c|c|}
\hline Category & & Parameters & GKM & LKM & $\begin{array}{l}\text { Change (GKM/ } \\
\text { LKM) }\end{array}$ & Average change \\
\hline \multirow[t]{9}{*}{ Structure features } & \multirow[t]{3}{*}{ Tree } & density, Td (ind. ha ${ }^{-1}$ ) & $2300(100) a$ & $1800(100) \mathrm{a}$ & 1.3 & \multirow[t]{3}{*}{1} \\
\hline & & height, Th (m) & $9.56(0.2) \mathrm{a}$ & $10.39(0.18) b$ & 0.9 & \\
\hline & & $\begin{array}{l}\text { diameter at breast height, } \\
\mathrm{DBH}(\mathrm{cm})\end{array}$ & $11(0.33) \mathrm{a}$ & $14.48(0.3) \mathrm{b}$ & 0.8 & \\
\hline & \multirow[t]{3}{*}{ Shrub } & density, Sd (ind. ha ${ }^{-1}$ ) & $22,100(1700) \mathrm{a}$ & $2700(1600) b$ & 8.2 & \multirow[t]{3}{*}{3} \\
\hline & & height, Sh (m) & $0.64(0.03) \mathrm{a}$ & $1.53(0.02) \mathrm{b}$ & 0.4 & \\
\hline & & coverage, Sc (\%) & $3.13(0.34) \mathrm{a}$ & $7.75(0.33) \mathrm{b}$ & 0.4 & \\
\hline & \multirow[t]{2}{*}{ Herb } & height, $\mathrm{Hh}(\mathrm{m})$ & $0.21(0.01) \mathrm{a}$ & $0.38(0.01) b$ & 0.6 & \multirow[t]{2}{*}{1.3} \\
\hline & & coverage, Hc (\%) & $15(1) \mathrm{a}$ & $7(1) b$ & 2.1 & \\
\hline & Fungi & density, $\mathrm{Md}$ (ind. $\mathrm{m}^{-2}$ ) & $0.1(0.01) \mathrm{a}$ & $0.03(0.01) b$ & 3.3 & 3.3 \\
\hline \multirow{16}{*}{ Species diversity } & \multirow{4}{*}{ Tree } & Shannon-Wiener, TH' & $0.71(0.02) \mathrm{a}$ & $0.77(0.02) \mathrm{a}$ & 0.9 & \multirow[t]{4}{*}{0.7} \\
\hline & & Simpson, TD & $0.4(0.02) \mathrm{a}$ & $0.75(0.02) b$ & 0.5 & \\
\hline & & richness, TR & $4(0.12) \mathrm{a}$ & $6(0.11) \mathrm{b}$ & 0.6 & \\
\hline & & evenness, TJsw & $0.57(0.01) \mathrm{a}$ & $0.61(0.01) b$ & 0.9 & \\
\hline & \multirow[t]{4}{*}{ Shrub } & Shannon-Wiener, SH' & $0.47(0.03) \mathrm{a}$ & $0.82(0.03) \mathrm{a}$ & 0.6 & \multirow[t]{4}{*}{0.7} \\
\hline & & Simpson, SD & $0.26(0.01) \mathrm{a}$ & $0.46(0.01) b$ & 0.6 & \\
\hline & & richness, SR & $3(0.11) \mathrm{a}$ & $3(0.1) b$ & 1 & \\
\hline & & evenness, SJsw & $0.42(0.02) \mathrm{a}$ & $0.7(0.02) b$ & 0.6 & \\
\hline & \multirow[t]{4}{*}{ Herb } & Shannon-Wiener, HH' & $1.88(0.04) \mathrm{a}$ & $1.92(0.03) \mathrm{a}$ & 1 & \multirow[t]{4}{*}{1} \\
\hline & & Simpson, HD & $0.76(0.01) \mathrm{a}$ & $0.75(0.01) b$ & 1 & \\
\hline & & richness, HR & $12(0.41) \mathrm{a}$ & $18(0.38) b$ & 0.7 & \\
\hline & & evenness, HJsw & $0.81(0.01) \mathrm{a}$ & $0.68(0.01) b$ & 1.2 & \\
\hline & \multirow[t]{4}{*}{ Fungi } & Shannon-Wiener, MH' & $2.85(0.12) \mathrm{a}$ & $0.83(0.12) b$ & 3.4 & \multirow[t]{4}{*}{3.2} \\
\hline & & Simpson, MD & $0.79(0.02) \mathrm{a}$ & $0.45(0.02) b$ & 1.8 & \\
\hline & & richness, MR & $15(1) \mathrm{a}$ & $4(1) b$ & 4 & \\
\hline & & evenness, MJSW & $1.06(0.03) \mathrm{a}$ & $0.3(0.03) \mathrm{a}$ & 3.5 & \\
\hline
\end{tabular}

The parameters include full names and abbreviations, standard errors are in parentheses behind mean values; average change is the mean of the changes for all parameters in each layer

management (Zhou 1997), the original climax vegetation in the LKM has changed with a sharp decline in Korean pine and numbers of other important species such as Franxinus mandshurica, Phellodendron amurense and Juglans mandshurica Maxim. (Zhou 1994). For the production of timber, a large area of secondary forest had a significant proportion of planted Larix gmelinii (Zhou et al. 1989). On heavily harvested sites, naturally regenerated Betula platyphylla was prevalent (Guan et al. 1997). In the history of the GKM, Larix gmelinii accounted for nearly $90 \%$ (Xu et al. 1997) in the 1950s, 66\% in 1987 and 48\% in 2003 (Liu 1990), birch increased from $12.6 \%$ in 1956 to $30.6 \%$ in 1987 and $36 \%$ in 2003 (Liu 1990; Chen et al. 2008) (Table 7). In this study, Betula platyphylla accounted for $20 \%$ with Larix gmelinii at $48 \%$. Betula platyphylla is a pioneer species, increasing significantly after logging (Zhou et al. 1989). The abundance of Larix gmelinii in the GKM was twice that of the LKM (Fig. 5), and larch is the main climax species in the region (Zhou 1997). The homogenization of species in the two regions was related to the anthropogenic influence of afforestation and over-harvest secondary succession. The ecological risks should be highlighted for this homogenization (McKinney 2006).

Shrubs and herbs are different in the two regions, which is similar to their original history (Table 7). Vaccinium vitisidaea prevailed in the GKM and Corylus spp. in the LKM (Zhou 1991) and are dominant today. However, the specific plant abundance declines should be noticed. For example, the percentage of Vaccinium uliginosum and Ledum palustre were sharply reduced in the GKM; herbs in the LKM were dominant by Deyeuxia purpurea, Carex spp. and Impatiens nolitangere, but the latter sharply decreased in our research (IV $<5 \%$ ). In the GKM, some changes in herbs were found when compared with historical data (Table 7) (Zhou and Zhou 1985); medicinal and wild vegetable species became less dominant. Vaccinium vitis-idaea, Rhododendron dauricum, Ledum palustre accounted for 6\%-21\% in current shrub layer, and Sanguisorba officinalis, Pyrola rotundifolia and Convallaria majalis were 4\%-5\% in the present herb layer in the GKM. In the LKM, Sorbaria sorbifolia was $8 \%$ of 
Table 5 Explanation of influence factors on plant species diversity

\begin{tabular}{|c|c|c|c|c|c|c|c|c|c|c|c|}
\hline \multicolumn{6}{|l|}{ GKM } & \multicolumn{6}{|l|}{ LKM } \\
\hline \multicolumn{3}{|c|}{ Simple Term Effects } & \multicolumn{3}{|c|}{ Conditional Term Effects } & \multicolumn{3}{|c|}{ Simple Term Effects } & \multicolumn{3}{|c|}{ Conditional Term Effects } \\
\hline Name & Explains \% & $P$ & Name & Explains \% & $P$ & Name & Explains \% & $P$ & Name & Explains \% & $P$ \\
\hline $\mathrm{Hc}$ & 22.7 & 0.002 & $\mathrm{Hc}$ & 22.7 & 0.002 & $\mathrm{Hc}$ & 10 & 0.002 & $\mathrm{Hc}$ & 10 & 0.002 \\
\hline $\mathrm{Sd}$ & 10.5 & 0.002 & LedumPal.A & 4.3 & 0.002 & DeyeuxiaP & 8.6 & 0.002 & DeyeuxiaP & 6.4 & 0.002 \\
\hline DeyeuxiaP & 10.2 & 0.002 & VacciniumV & 4.1 & 0.002 & CorylusM & 5.5 & 0.002 & CorylusM & 5.6 & 0.002 \\
\hline LedumPal.A & 8.4 & 0.002 & LarixG & 3.1 & 0.002 & LarixG & 4.3 & 0.002 & CaldesiaP & 4.1 & 0.002 \\
\hline VacciniumV & 7.6 & 0.002 & QuercusM & 2.1 & 0.004 & CaldesiaP & 3.4 & 0.002 & CarexD & 3.9 & 0.002 \\
\hline LarixG & 6.9 & 0.002 & CorylusH & 1.8 & 0.002 & $\mathrm{Hh}$ & 3.3 & 0.002 & LarixG & 2.8 & 0.002 \\
\hline Sh & 5.2 & 0.002 & DeyeuxiaP & 1.1 & 0.014 & SpiraeaS & 2.9 & 0.002 & Th & 2.1 & 0.002 \\
\hline QuercusM & 3.2 & 0.002 & Tdbh & 1.1 & 0.008 & Tdbh & 2.8 & 0.002 & SpiraeaS & 1.8 & 0.002 \\
\hline CorylusH & 2.9 & 0.002 & FragariaO & 0.9 & 0.03 & QuercusM & 2.7 & 0.002 & CorylusH & 2.1 & 0.002 \\
\hline BetulaP & 2.8 & 0.002 & $\mathrm{Sd}$ & 0.9 & 0.03 & Th & 1.9 & 0.004 & $\mathrm{Hh}$ & 1 & 0.004 \\
\hline FragariaO & 2.5 & 0.002 & $\mathrm{Hh}$ & 0.7 & 0.042 & $\mathrm{Sd}$ & 1.8 & 0.004 & PopulusD & 1 & 0.01 \\
\hline $\mathrm{Sc}$ & 2.4 & 0.004 & Sc & 0.7 & 0.036 & SorbariaS & 1.7 & 0.006 & BetulaP & 1 & 0.006 \\
\hline Rhodod.D & 1.7 & 0.006 & & & & CarexD & 1.7 & 0.004 & PinusK & 1.6 & 0.002 \\
\hline CarexC & 1.6 & 0.01 & & & & PinusK & 1.7 & 0.006 & QuercusM & 2.8 & 0.002 \\
\hline PopulusD & 1.5 & 0.012 & & & & FilipendulaP & 1.6 & 0.004 & $\mathrm{Sd}$ & 0.9 & 0.006 \\
\hline SanguisorbaO & 1.5 & 0.01 & & & & BetulaP & 1.2 & 0.02 & FilipendulaP & 0.8 & 0.01 \\
\hline Tdbh & 1.2 & 0.034 & & & & EquisetumS & 1.1 & 0.04 & $\mathrm{Td}$ & 0.6 & 0.026 \\
\hline SpiraeaM & 1.2 & 0.044 & & & & Sh & 1.1 & 0.032 & & & \\
\hline
\end{tabular}

The parameters not statistically significant $(p>0.05)$ were excluded; the abbreviations can be seen in Fig. 9

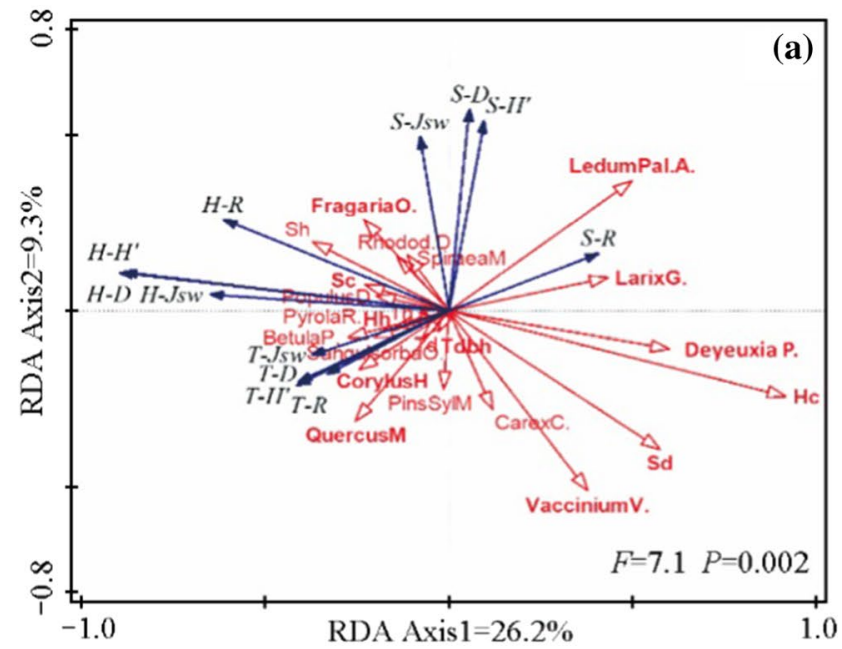

Fig. 9 RDA analysis of stand structure, dominant species and plant diversity variations in the GKM (a) and the LKM (b). Notes Factors in bold are the significant elements under conditional effects; species diversity abbreviation: T-H' S-H' and H-H', Shannon-Wiener index of tree, shrub and herb layers; T-D, S-D and H-D, Simpson index of tree, shrub and herb layers; T-R, S-R and H-R, richness of tree, shrub and herb layers; T-Jsw, S-Jsw and H-Jsw, evenness index of tree, shrub and herb layers; stand structural features include Tdbh, diameter at breast height; Th, tree height; Td, tree density; Sh, shrub height; Sd, shrub density; Sc, shrub coverage; Hh, herb height; Hc, herb coverage. Dominant species abbreviation: PinsSylM., Pinus sylvestris var. mongolica; BetulaP, Betula platyphylla; PinusK.,

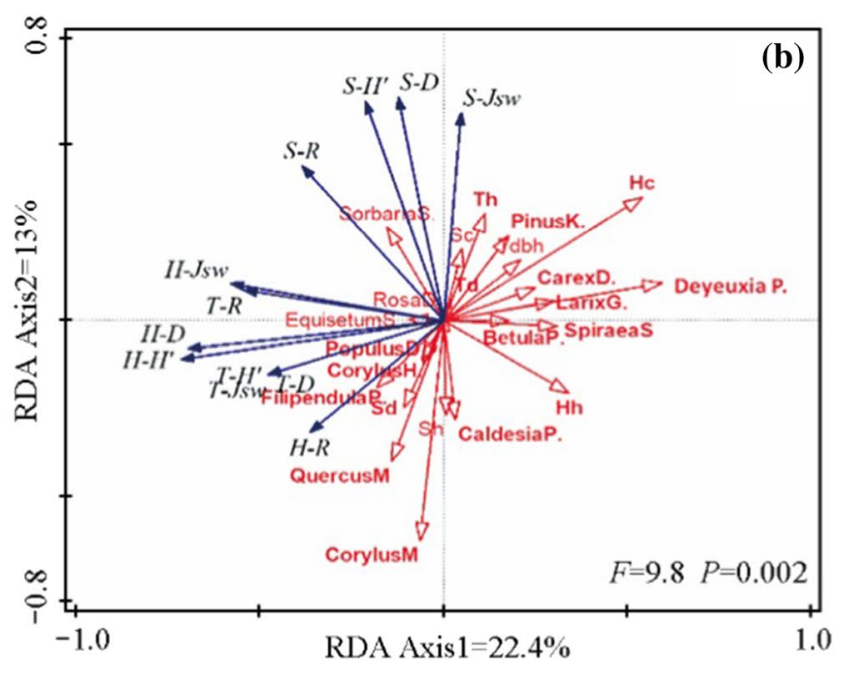

Pinus koraiensis; LarixG, Larix gmelinii; QuercusM, Quercus mongolica; PopulusD., Populus davidiana; SpiraeaM., Spiraea media; LedumPal.A., Ledum palustre; Rhodod.D, Rhododendron dauricum; VacciniumV, Vaccinium vitis-idaea; CorylusM, Corylus mandshurica; RosaD, Rosa davurica; SpiraeaS., Spiraea salicifolia; SorbariaS., Sorbaria sorbifolia; CorylusH., Corylus heterophylla; SanguisorbaO., Sanguisorba officinalis; FragariaO, Fragaria orientalis; CarexC, Carex callitrichos; PyrolaR., Pyrola rotundifolia; EquisetumS., Equisetum sylvaticum; FilipendulaP., Filipendula palmate; DeyeuxiaP., Deyeuxia purpurea; CaldesiaP., Caldesia parnassifolia; CarexD., Carex dispalata 
Table 6 Impact factors on macrofungi diversity; parameters not statistically significant are excluded (abbreviations in Figs. 9 and 10)

\begin{tabular}{|c|c|c|c|c|c|}
\hline \multicolumn{3}{|c|}{ Simple Term Effects } & \multicolumn{3}{|c|}{ Conditional Term Effects } \\
\hline Name & Explains \% & $P$ & Name & Explains \% & $P$ \\
\hline \multicolumn{6}{|l|}{$G K M$} \\
\hline VacciniumV & 6.4 & 0.004 & VacciniumV & 6.4 & 0.002 \\
\hline $\mathrm{Hc}$ & 6 & 0.008 & LarixG & 5.7 & 0.004 \\
\hline $\mathrm{Td}$ & 5.8 & 0.012 & $\mathrm{Td}$ & 5.4 & 0.016 \\
\hline Sh & 5.8 & 0.02 & $\mathrm{Sh}$ & 5.3 & 0.024 \\
\hline LarixG & 5.7 & 0.012 & & & \\
\hline Sc & 5.1 & 0.02 & & & \\
\hline H-R & 4.6 & 0.022 & & & \\
\hline SpiraeaM & 4.2 & 0.036 & & & \\
\hline $\mathrm{H}-\mathrm{D}$ & 4.2 & 0.022 & & & \\
\hline S-Jsw & 3.8 & 0.04 & & & \\
\hline \multicolumn{6}{|l|}{$L K M$} \\
\hline Tdbh & 4.1 & 0.032 & Tdbh & 4.1 & 0.026 \\
\hline SorbariaS & 3.5 & 0.03 & T-D & 4.7 & 0.012 \\
\hline $\mathrm{Td}$ & 2.4 & 0.11 & SorbariaS & 2.7 & 0.084 \\
\hline
\end{tabular}

the shrub layer, and Filipendula palmata for $9 \%$ of the herb layer. Their past abundance was much higher than it is today (Chinese-Herbal-Medicine-Teaching-and-Research-Office 1973; Nie 1980).

Species diversity in the LKM is higher than in the GKM today which is similar to historical records (Table 8). There

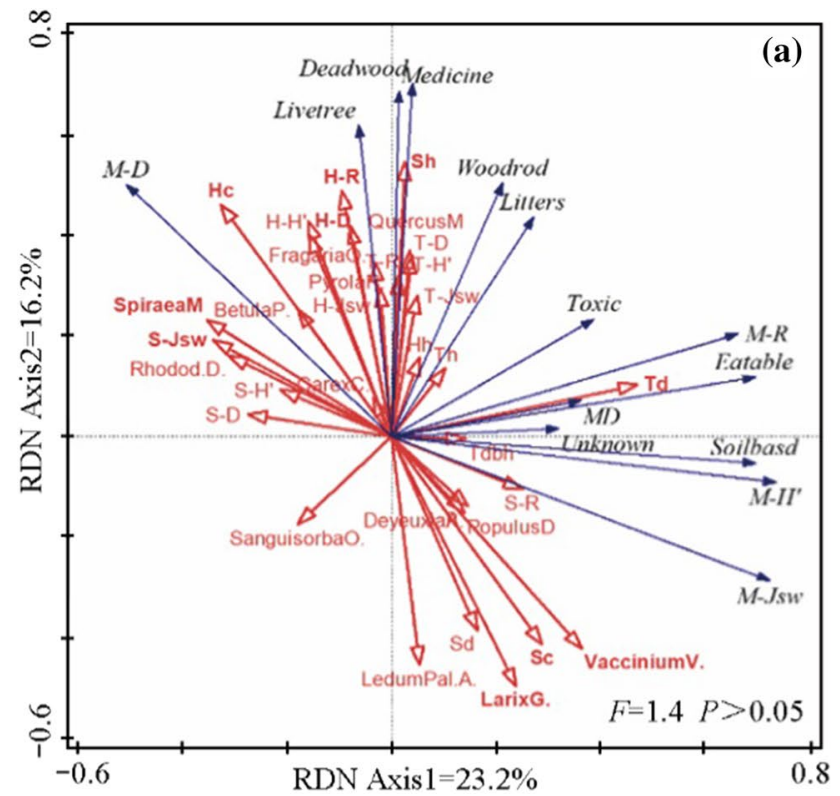

Fig. 10 RDA analysis of forest plant features and macrofungi parameters in the GKM (a) and LKM (b). Notes Factors in bold are the significant elements under simple and conditional effects; plant features include stand structure, dominant species composition and diversity characteristics (abbreviations in Fig. 9); macrofungi parameters was $10-50 \%$ less diversity of trees, shrubs and herbs, but herbs are distributed more evenly in the GKM. The total number of plant species recorded in this study (369-384) is much lower than the historical record (1003-1377 species, Table 8). This field study is part of a national project with national top-level scientists. However, in the 1950s-1970s, large-scale field studies with special emphasis on taxonomical identification were carried out by different teams, and the combined work of several taxonomists resulted in more detailed (http://www.iplant.cn/frps2019/). Another reason for species differences is due to the extinction of some species owing to excessive human disturbance (e.g., wild ginseng) and global climate changes (Pandolfi et al. 2020).

In conclusion, much denser forests of smaller sized trees were found in the GKM compared to the LKM, and forest layers were only half the heights in both regions compared with historical data (Table 9). In the case of tree height, annual rates of declining were $26.5 \mathrm{~cm}$ and $17.7 \mathrm{~cm}$ in the GKM and LKM; with DBH, annual rates of declining were $2.6 \mathrm{~mm}$ and $3.1 \mathrm{~mm}$ in the two regions, respectively (Table 9). The better forest structure usually means higher canopy, and good forest structure for forest ecological services is just as black soil thickness's importance for farmland productivity. When considering black soil erosion crisis, the $0.3 \mathrm{~cm}$ year $^{-1}$ erosion is usually mentioned (https://china. huanqiu.com/article/9CaKrnJBY9x). Our results show that forest degradation is 18-88-times higher than black soil degradation in this region (Table 9). Furthermore, our data

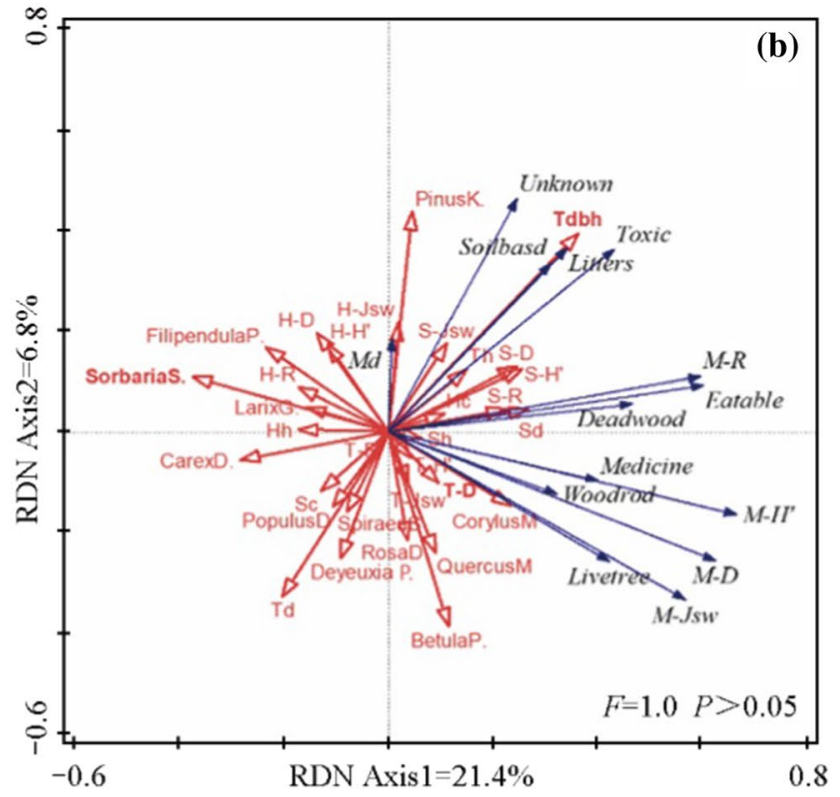

include macrofungi diversity: Shannon-Wiener (M-H'), Simpson (M-D), richness (M-R) and evenness index (M-Jsw); macrofungi functional groups include edible, medicine, toxic, wood rot and Unknown; habitat: living tree (Livetree), Deadwood, soil-based, litter-habitat (Litters) macrofungi, and macrofungi density (Md) 
Table 7 Comparison of species composition based on historical and present data in GKM and LKM

\begin{tabular}{|c|c|c|c|}
\hline \multicolumn{2}{|l|}{ Region } & \multirow{2}{*}{$\begin{array}{l}\text { Current study } \\
\text { Larix gmelinii (43\%), Betula platyphylla }(30 \%)\end{array}$} & \multirow{2}{*}{$\begin{array}{l}\text { Past study } \\
\begin{array}{l}\text { Larix gmelinii }(90 \% \text { in } 1950 ; 48 \% \text { in } 2003), \text { Betula platy- } \\
\text { phylla }(12.6 \% \text { in } 1956 ; 36 \% \text { in } 2003)\end{array}\end{array}$} \\
\hline GKM & $\mathrm{T}$ & & \\
\hline & $\mathrm{S}$ & $\begin{array}{l}\text { Vaccinium spp., Corylus heterophylla; Spiraea spp., Rho- } \\
\text { dodendron spp. and Ledum spp. }\end{array}$ & $\begin{array}{l}\text { Vaccinium spp., Ledum spp., Rhododendron spp. With } \\
\text { more Lonicera spp., and Eleutherococcus senticosus }\end{array}$ \\
\hline & $\mathrm{H}$ & $\begin{array}{l}\text { Deyeuxia purpurea, Carex callitrichos, Sanguisorba } \\
\text { officinalis, Pyrola rotundifolia, Fragaria orientalis }\end{array}$ & $\begin{array}{l}\text { Leymus chinensis, Trientalis europaea, Maianthemum } \\
\text { bifolium, Linnaea borealis, Goodyera repens }\end{array}$ \\
\hline & M & $\begin{array}{l}\text { Cortinarius tenuipes, Cortinarius croceofolius, Laccaria } \\
\text { proxima, Cortinarius varius }\end{array}$ & - \\
\hline \multirow[t]{4}{*}{ LKM } & $\mathrm{T}$ & $\begin{array}{l}\text { Larix gmelinii }(22 \%), \text { Betula platyphylla }(22 \%), \text { Pinus } \\
\text { koraiensis }(6 \%)\end{array}$ & $\begin{array}{l}\text { Pinus koraiensis }(15-50 \%, 1960 \text { to -1980), Quercus mon- } \\
\text { golica }(20 \%)\end{array}$ \\
\hline & $\mathrm{S}$ & $\begin{array}{l}\text { Spiraea salicifolia, Corylus spp., Sorbaria sorbifolia, } \\
\text { Rosa davurica }\end{array}$ & $\begin{array}{l}\text { Corylus spp., Philadelphus schrenkii, Lonicera chrysantha, } \\
\text { Eleutherococcus senticosus, Deutzia spp. }\end{array}$ \\
\hline & $\mathrm{H}$ & $\begin{array}{l}\text { Deyeuxia purpurea, Caldesia parnassifolia, Filipendula } \\
\text { palmata, Carex dispalata, Equisetum sylvaticum }\end{array}$ & $\begin{array}{l}\text { Carex quadriflora, Carex lanceolata, Carex ussuriensis, } \\
\text { Equisetum sylvalicum }\end{array}$ \\
\hline & $\mathrm{M}$ & $\begin{array}{l}\text { Fomes fomentarius, Collybia acervata, Coriolus versi- } \\
\text { color }\end{array}$ & $\begin{array}{l}\text { Coriolus versicolor, Fomes fomentarius, Ganoderma appla- } \\
\text { natum, Pleurotus ostreatus }\end{array}$ \\
\hline
\end{tabular}

-, indicates absence of related research; T, S, H and M: tree, shrub, herb and macrofungi respectively; ratios in parentheses indicate relative abundance; historical data referred to (Wei et al. 1994; Bi et al. 2006; Sun 2006)

Table 8 Comparison of species diversity based on historical and present data in the GKM and LKM

\begin{tabular}{lllllll}
\hline Factor & \multicolumn{2}{l}{ GKM } & & \multicolumn{2}{l}{ LKM } \\
\cline { 2 - 3 } \cline { 5 - 6 } & This study & History & & This study & History \\
\hline Tree Simpson & 0.40 & $0.60(2003)$ & & 0.75 & $0.69(2007)$ \\
Tree Shannon-wiener & 0.71 & $1.01(2002)$ & & 0.77 & $0.84(2007)$ \\
Tree evenness & 0.57 & $0.56(2002)$ & & 0.61 & - \\
Tree richness & 4 & $5(2000)$ & & 6 & $4(2007)$ \\
Shrub Simpson index & 0.26 & $0.67(2003)$ & & 0.46 & $0.58(2007)$ \\
Shrub Shannon-wiener & 0.47 & $0.88(2001)$ & & 0.82 & $1.05(2007)$ \\
Shrub evenness & 0.42 & $0.77(2001)$ & & 0.70 & - \\
Shrub richness & 3 & $5(2000)$ & & 3 & $5(2007)$ \\
Herb Simpson & 0.76 & $1.03(2003)$ & & 0.75 & $0.81(2007)$ \\
Herb Shannon-wiener & 1.88 & $1.46(2001)$ & & 1.92 & $1.73(2007)$ \\
Herb evenness & 0.81 & $0.68(2001)$ & & 0.68 & - \\
Herb richness & 12 & $15(2000)$ & & 18 & 23 (2007) \\
Taxonomy species number & 384 & $1377($ Sun 2006) & & 369 & 1003 (Zhou 1994) \\
\hline
\end{tabular}

-, Indicates lack of related research; Numbers in brackets is the reference year; historical diversity data referred to Ma et al. (2000), Song and Yang (2001), Zhang et al. (2007) and Chen et al. 2008 also found that shrubs and herbs became much shorter than historically (Table 9). Over all, forest degradation related to forest structure in both regions needs more attention for the ecological well-being of the northeast forest belt.

\section{Macrofungi in the two regions: differences and comparison}

Compared with the LKM, macrofungal abundance was 1.3-10 times higher in the GKM except for living tree habitat macrofungi. This is possibly related to human impact differences. The population density in the GKM is 60 thousand people per $\mathrm{km}^{2},<1 / 3$ of the LKM (190 thousand people per $\mathrm{km}^{2}$ ). Historical records have shown a contrasting tendency with macrofungi species in the GKM lower than in the LKM (471 vs 578, Table 10). Macrofungi in LKM need to be protected in the future.

References have shown a similar species composition compared with our data. Different surveys in the GKM have reported 201-452 species, and a macrofungi list of 210-713 was found in the LKM (Table 10). In the Huzhong and Liangshui Reserves, not all previous lists were found in our research owing to lists of previous reports compiled by different scientists and sampled in different seasons. Until 
Table 9 Comparison of historical and present data of plant size in the GKM and LKM

\begin{tabular}{llllll}
\hline Parameter & & Tree height $(\mathrm{m})$ & Tree DBH $(\mathrm{cm})$ & Shrub height $(\mathrm{m})$ & $\begin{array}{l}\text { Herb height } \\
(\mathrm{m})\end{array}$ \\
\hline GKM & History & $22.6(1969)$ & $23.1(1972)$ & $0.8(1965)$ & $0.4(1964)$ \\
& Now & $9.6(2018)$ & $11.0(2018)$ & $0.6(2018)$ & $0.2(2018)$ \\
& Rate & $-26.5 \mathrm{~cm} \mathrm{year}^{-1}$ & $-2.6 \mathrm{~mm} \mathrm{year}^{-1}$ & $-0.4 \mathrm{~cm} \mathrm{year}^{-1}$ & $-0.4 \mathrm{~cm} \mathrm{year}^{-1}$ \\
& $P$ value & $P<0.05$ & $P<0.05$ & $P>0.05$ & $P>0.05$ \\
LKM & History & $20.5(1961)$ & $31.9(1961)$ & $1.8(1954)$ & $0.9(1954)$ \\
& Now & $10.4(2018)$ & $14.5(2018)$ & $1.5(2018)$ & $0.4(2018)$ \\
& Rate & $-17.7 \mathrm{~cm} \mathrm{year}^{-1}$ & $-3.1 \mathrm{~mm} \mathrm{year}^{-1}$ & $-0.5 \mathrm{~cm} \mathrm{year}^{-1}$ & $-0.8 \mathrm{~cm}_{\mathrm{year}}{ }^{-1}$ \\
& $P$ value & $P<0.05$ & $P<0.05$ & $P<0.05$ & $P<0.05$ \\
\hline
\end{tabular}

Data in parenthesis is year of measurement; rate is declined rate calculated by value in the history data/ (2018 time) (Huang 1959; Wang et al. 1959; Shao et al. 1960; Zhou and Li 1964; Zhou and Zhao 1964; Zhang 1965; Li 1982; Zhao et al. 1987; Zhou 1991, 1994; Song and Liu 1995)

Table 10 Macrofungi data of previous publications and comparison with present study

\begin{tabular}{|c|c|c|c|}
\hline GKM & Macrofungi data & LKM & Macrofungi data \\
\hline $\begin{array}{l}\text { Whole GKM Region (https:// } \\
\text { wenku.baidu.com/view/b5596 } \\
\text { dd176232f60ddccda38376baf } \\
\text { 1ffc4fe3e0.html) }\end{array}$ & $\begin{array}{l}2 \text { phyla, } 15 \text { orders, } 47 \text { families, } \\
132 \text { genera, } 452 \text { species }\end{array}$ & Whole LKM Region (Zhang 2017) & $\begin{array}{l}2 \text { phylum, } 5 \text { classes, } 21 \text { orders, } 65 \\
\text { families, } 197 \text { genera, } 713 \text { species }\end{array}$ \\
\hline $\begin{array}{l}\text { Nanwenhe National Nature } \\
\text { Reserve (Liu 2013) }\end{array}$ & $\begin{array}{l}2 \text { phyla, } 4 \text { classes, } 17 \text { orders, } 50 \\
\text { families, } 87 \text { genera, } 201 \text { species }\end{array}$ & $\begin{array}{c}\text { Shengshan National Nature } \\
\text { Reserve (Cheng 2018) }\end{array}$ & $\begin{array}{l}2 \text { phyla, } 5 \text { classes, } 14 \text { orders, } 47 \\
\text { families, } 84 \text { genera, } 213 \text { species }\end{array}$ \\
\hline $\begin{array}{l}\text { Larch forests in GKM (Yang et al. } \\
\text { 2017b) }\end{array}$ & $\begin{array}{l}4 \text { phyla, } 11 \text { classes, } 36 \text { orders, } 63 \\
\text { families, } 74 \text { genera, } 201 \text { species }\end{array}$ & $\begin{array}{l}\text { Mudanfeng National Nature } \\
\text { Reserve (Ma 2013) }\end{array}$ & $\begin{array}{l}3 \text { phyla, } 6 \text { classes, } 19 \text { orders, } \\
48 \text { families, } 98 \text { genus and } 210 \\
\text { species }\end{array}$ \\
\hline $\begin{array}{l}\text { Huzhong National Nature Reserve } \\
\text { (Li et al. 2011) }\end{array}$ & 7 orders, 31 families, 411 species & $\begin{array}{l}\text { Liangshui National Nature } \\
\text { Reserve (https://ls.nefu.edu.cn/) }\end{array}$ & $\begin{array}{l}7 \text { classes, } 21 \text { orders, and } 59 \text { fami- } \\
\text { lies, } 578 \text { species }\end{array}$ \\
\hline Our study & 7 orders, 24 families, 208 species & Our study & 10 orders, 32 families, 141 species \\
\hline
\end{tabular}

recently, the protection of natural reserves in China has been specified for threatened plants or animals (http://www.gov. cn/guoqing/2019-04/09/content_5380702.htm), without including macrofungi. Most previous studies have focused on macrofungi alone with multiple field surveys together with historical specimen identification. However, these studies did not include a regional comparison of macrofungi and plant diversity, and a detailed understanding of macrofungi and plant resources in taxon, structure and diversity as in this study, improves understanding of conservation of plant and macrofungi diversity.

\section{Implications of this study}

First of all, the understory contributes significantly forest community diversity, and more attention should be given to biodiversity conservation practices. Plant diversity, rather than macrofungi diversity, was easier explained by aboveground features. The understory forest economy of shrubs, herbs and macrofungal resources is developing rapidly (Bau et al. 2019). One concern is that this may lead to the over-exploitation of understory species, just as timber resources were historically over harvested (Zhou 1997). Our findings have clearly shown that over harvesting has resulted in changes in dominant tree species and the climax Korean pine has become a national species for protection. The same concern is that the extinction of understory species in the implementation of the NFPP. The conservation of understory resources should be considered in future forest resource management.

Secondly, association decoupling found differences between the two regions and provides guidance for improved and targeted management, which has been strongly encouraged by China's central government (http://www.forestry. gov.cn/). In both regions, herb cover was the main explanation for diversity variations, indicating the importance of protecting the herb layer in in the two regions. However, a second layer of species composition was different in the two regions; i.e., for the GKM, it was Vaccinium vitis-idaea and Ledum palustre, and for LKM, it was Deyeuxia angustifolia, Carex dispalata, and Caldesia parnassifolia. Plant diversity conservation may benefit from the regulation of these species in both regions. For macrofungi management, higher density forests as well as more Vaccinium vitis-idaea and 
Larix gmelinii will benefit the diversified macrofungi in the GKM. However, in the LKM, higher tree DBH and diversity will accompany much richer macrofungi of function groups and habitat-related types.

Thirdly, some parameters are major indicators of plant and macrofungi diversity but differ in the two regions. Such indicators can facilitate the evaluation of natural conservation efforts. In recent years, some researchers have proposed to monitor changes in forest diversity with macrofungi as a substitute (Halme et al. 2017), and our data confirms that higher plant diversity is accompanied with higher macrofungi Simpson indices, more abundance of habitat-related macrofungi groups, and different utilization-related functional groups in the GKM. In the LKM, higher tree-shrub diversity but fewer herbs were aligned with richer and diverse macrofungi functional groups. This provides an indicator-related basis for monitoring changes in forest diversity using multiple methods, which is important for the further implementation of the Natural Forest Protection Program.

\section{Conclusion}

Although climax vegetation in the GKM (larch forests) and LKM (Korean pine-broadleaf mixed forests) is historically different, our data shows similar dominant species of Larix gmelinii and Betula platyphylla. Moreover, in the past half-century, the canopy height decreased from 0.2 to $0.3 \mathrm{~cm}_{\text {year }}{ }^{-1}$, and the shrub-herb layers by $0.4-0.8 \mathrm{~cm}$ year $^{-1}$. Herb, shrub and macrofungi species in the GKM are considerably different from those in the LKM, which are similar to those historically. Complex associations between plant and macrofungi diversity and forest geographical location were observed, but significantly different explaining factors were found in these two regions. In both, the predominant explaining factor was herb cover, showing species importance for biodiversity conservation, and overemphasis on understory utilization should be cautioned. Our findings provide detailed data for the evaluation of natural resources utilization and biodiversity, and also provide information for further implementations of the NFPP.

Acknowledgements We would like to thank Hongju Du, Jianyu Zhang and many other students for their dedication to our fieldwork. Acknowledgements are also due to Prof. Cunti Xiang (retired from Northeast Forestry University) for his kind help on macrofungi recognition.

Open Access This article is licensed under a Creative Commons Attribution 4.0 International License, which permits use, sharing, adaptation, distribution and reproduction in any medium or format, as long as you give appropriate credit to the original author(s) and the source, provide a link to the Creative Commons licence, and indicate if changes were made. The images or other third party material in this article are included in the article's Creative Commons licence, unless indicated otherwise in a credit line to the material. If material is not included in the article's Creative Commons licence and your intended use is not permitted by statutory regulation or exceeds the permitted use, you will need to obtain permission directly from the copyright holder. To view a copy of this licence, visit http://creativecommons.org/licenses/by/4.0/.

\section{References}

Ali A, Lin SL, He JK, Kong FM, Yu JH, Jiang HS (2018) Climate and soils determine aboveground biomass indirectly via species diversity and stand structural complexity in tropical forests. For Ecol Manage 432:823-831. https://doi.org/10.1016/j.foreco.2018. 10.024

Bau T, Li Y (2000) Fungal community diversity in Daqinggou Nature Reserve. Acta Ecol Sin 20(6):986-991

Bau T, Li Y (2010) Wild eatible mushroom resources in Norhteastern China. In: Eatible mushroom symposium of China

Bau T, Wang X, Zhang P (2019) Floristic of agarics and boletus in the Greater and Lesser Khinggan Mountains. Biodivers Sci 27(8):867-873. https://doi.org/10.17520/biods.(2019)048

Bi XH, Wei X, Deng X (2006) Ecological distribution and resource evaluation of macrofungi in Natural Korean pine forests in Heilongjiang Province. For Sci Technol 31(5):26-30

Chen RJ, Ming HJ, Wang JN (2008) Research on forest structure characteristics in Inner Mongolia Daxing'an mountains. Inner Mong For Investig Des 31(1):56-58. https://doi.org/10.13387/j.cnki

Chen KL, Mao XL, Huang MD (2013) A guide to large antitumor medicinal fungi in China. Science Press, Beijing

Cheng GH (2018) Macrofungi diversity of Shengshan National Natural Reserve. Jilin Agriculture University, Changchun, Heilongjiang Province

Chinese Herbal Medicine Teaching and Research Office (1973) Medicinal plants of Daxing'an Mountains. J Shenyang Pharm Univ $1: 35-77$

Deng X (2010) Macrofungi In Daxinganling Mts-economic fungi. Northeast Forestry University Press, Harbin

Fu PY (2004) Herbs of Northeast China. Science Press

Fu YY, Zhao JJ, Zhang HY, He HS, Guo XY (2016) Spatiotemporal variation of vegetation phenology in the Daxing' an Mountains stratified by eco-geographical regions. Chin J Appl Ecol 27(9):2797-2806

Gu Y, Han SJ, Zhang JH, Chen ZJ, Wang WJ, Feng Y, Jiang YG, Geng SC (2020) Temperature-dominated driving mechanisms of the plant diversity in temperate forests. Northeast China For 11(2):227. https://doi.org/10.3390/f11020227

Guan WB, Chen T, Dong YK, Zhou YL (1997) Vegetation diversity in northeastern China I. Diversity of vertical vegetation composition in cold temperate coniferous forest region. Chin J Appl Ecol 8(5):465-470. https://doi.org/10.13287/j.1001

Halme P, Holec J, Clausen JH (2017) The history and future of fungi as biodiversity surrogates in forests. Fungal Ecol 27:193-201. https://doi.org/10.1016/j.funeco.(2016).10.005

Han J, Wen RY, Chi ZY (2004) A brief discussion on forest vegetation distribution in Da, XiaoXing' an mountains. Inner Mongolia Sci Technol Econ 16:111-113

Huang JB (1959) A brief introduction of the natural geographical landscape of Arshan area in the south of Daxinganling Mountains. For Sci 6:446-451

Huang NL (1998) Primary color map of Chinese macrofungi. China Agriculture Press, Beijing

Kirk PM, Cannon PF, Minter DW, Stalper JA, Andrianova TV, Aptroot A, Benny GL (2008) Dictionary of the Fungi. CAB internationalEurope UK, Wallingford

Li WH (1982) Study on the community structure of larch forest in the south slope of Xiaoxing' an mountains. J Beijing For Univ 3:42-51 
Li XP, Wang LJ, Wei L, Xu TJ (2011) A Study on macrofungi resources in Huzhong Nature Reserve. For Sci Technol Inf 43(03):12-13

Liu SE (1955) Flora of woody plants in northeast China: Science Press Liu HF (1990) 30 years' change of forest resources in Daxing' an mountains forests. Forest Resour Manag 1:20-26

Liu XD (2004) Color atlas of wild macrofungi in China. China Forestry Publishing House, Beijing

Liu LX (2012) Study on the ecological functional service value of plant diversity of forest ecosystem in Xiaoxinganling. Northeast Forestry University

Liu HH (2013) Macrofungi diversity of Heilongjiang Nanwenhe national nature Reserve. Jilin Argricultural University, Changchun

Ma F (2013) Macrofungi diversity of Mudanfeng national nature reserve of Heilongjiang province. Jilin Agricultural University, Changchun

Ma KP, Huang JH, Yu SL, Chen LZ (1995) Study on Richness, Evenness and Species diversity index of plant community diversity in Dongling Mountain. Beijing Acta Ecol Sin 15(3):268-277

Ma JY, Feng XQ, Guo YC (2000) Study on species diversity of primitive spruce forest in Daxinganling Mountains. For Investig Des $1: 54-55$

Mao XL (2000) The macrofungi In China. Science and Technology Publishing House of Henan Province, Zhengzhou

Mao ZH, Zhu JJ (2006) Effects of disturbances on species composition and diversity of plant communities. Acta Ecol Sin 26(8):2695-2701

McKinney ML (2006) Urbanization as a major cause of biotic homogenization. Biol Cons 127(3):247-260. https://doi.org/10.1016/j. biocon.(2005).09.005

Mysological Society of China (2016) Nanhua Declaration on the Wild Mushrooms Conservation. Accessed (2016)

Nature Museum Editorial Board (2014) Mushroom. Chemical Industrial Press, Beijing

Nie SQ (1980) Medicinal plants of northeastern forests. Nat Resour Res 2:30-35

Pandolfi JM, Staples TL, Kiessling W (2020) Increased extinction in the emergence of novel ecological communities. Science 370(6513):220-222. https://doi.org/10.1126/science.abb3996

Qian XY (2014) Analysis of forestry resources and non-wood fiber supply in China. China Pulp Paper Ind 9:23-27

Ren LJ, Li GT, Sun XJ, Yu SP, Zheng XW, Yue YJ (2013) Research on community structure and species diversity of Larix gmelinii community in Inner Mongolia Daxing'anling Mountains. Forest Resour Manag 3:83-118. https://doi.org/10.13466/j.cnki.lyzygl. (2013).03.023

Shao J, Wang Z, Zhao YH (1960) Logging and reforestation in Northeast China. For Sci 3:200-207

Shao LP, Xiang CT (1997) Forest mushroom of China. Northeast Forestry University Press, Harbin

Shao LP, Xiang CT (2017) China Forest Mushroom. Northeast Forestry University Press, Harbin

Song GL, Yang GT (2001) Comparison of species diversity between Larix gmelini pure forest and Larix gmelini-Betula platyphylla mixed forest in Daxing' an Mountains. J For Res 12(2):136-138

Song P, Liu Z (1995) Research on forest plant resources and their development and utilization in Daxing' an mountains. Inner Mongolia For Investig Des 4(27):24-27

Sun JX, Du HJ, Zhang JY, Xiang CT, Wang WJ (2020) Survey of fungal resources in Huzhong National Nature Reserve and adjacent areas of Daxing' an Mountains. Edible Fungi 42(2):20-27

Sun MX (2006) Forest plants of Daxinganling. Northeast Forestry University Press

Tobner CM, Paquette A, Gravel D, Reich PB, Williams LJ, Messier C (2016) Functional identity is the main driver of diversity effects in young tree communities. Ecol Lett 19(6):638-647. https://doi. org/10.1111/ele. 12600
Wang WJ (2019) Harbin urban forest characteristics and ecological service functions. Science Press, Beijing, China

Wang ZS, Zheng FK, Shi C, Lv ZZ (1959) Preliminary investigation of pinus bungeana plantation in Caohekou Forest Region. For Sci 3:172-181

Wang XG, Zhang TX, Wang B (2012) Eatible mushroon industry development in NE China and future prospect. North Hortic 9:203-205

Wang Q, Zhang D, Zhou W, He XY, Wang WJ (2020a) Urbanization led to a decline in glomalin-soil-carbon sequestration and responsible factors examination in Changchun, Northeastern China. Urban For Urban Green 48:126506. https://doi.org/10. 1016/j.ufug.(2019).126506

Wang YY, Yu JH, Xiao L, Zhong ZL, Wang Q, Wang WJ (2020b) Dominant species abundance, vertical structure and plant diversity response to nature forest protection in Northeastern China: conservation effects and implications. Forests 11(3):295. https:// doi.org/10.3390/f11030295

Wei SC, Wang QY, Liu XZ, Zhang YL, Fan F (1994) Differentiation of vegetation on the east and west sides of the middle part of the Daxingan Mountains. Acta Pratacul Sin 3(2):12-19

Wu F, Zhou LW, Yang ZL, Bau T, Li T, Dai YC (2019) Resource diversity of Chinese macrofungi: edible, medicinal and poisonous species. Fungal Divers 98:1-76

Xiang CT (2005) Wild eatable mushroom. China Forestry Publishing House, Beijing

Xie ZG (2017) Research on original forest flora and floristic geographic elements in the North Greater Hinggan mountains of Inner Mongolia. For Resour Manag 2:88-92

Xu HC, Li Z, Qiu Y (1997) Fire disturbance history in virgin forest in northern region of Daxinganling Mountains. Acta Ecol Sin 17(4):337-343

$\mathrm{Xu}$ LN, Jin GZ (2012) Species composition and community structure of a typical mixed broadleaved-Korean pine (Pinus koraiensis) forest plot in Liangshui Nature Reserve. Northeast China Biodivers Sci 20(4):470-481

Yang Y (2018) Discussion on the present situation and measures of forest pest control. South China Agric 12(33):66-67. https://doi. org/10.19415/j.cnki.1673-890x.(2018).33.035

Yang Y (2019) Study on the effects of fire on forest carbon stocks, plant composition diversity and community structure in Daxingan Mountains. Northeast Forestry University

Yang HS, Wang CB, Qi XL, Wang CP (2017a) Floristic study of rosaceae in the Xiaoxing' an mountains. J Anhui Agric Sci 45(15):4-5

Yang LB, Sui X, Zhu DG, Cui FX, Li JB, Song RQ (2017b) Study on fungal communities characteristics of different Larix gmelini forest typesin cold temperate zone. J Central South Univ For Technol 37(12):76-84

Yang YB, Lv HL, Fu Y, He XY, Wang WJ (2019) Associations between road density, urban forest landscapes, and structuraltaxonomic attributes in Northeastern China: decoupling and Implications. Forests 10(1):58

Yu T, Wang W, Zhao BS, Lian J (2005) Economic mcrofungi in Daxinganling Mts in Inner monglica. Northeast Forestry University Press, Harbin

Zhang L, Yuan XY, Zhang DL (2007) The species diversity of the floras of Daxing' an Mountain, Xiaoxing'an Mountain and Ecotone. Bull Bot Res 27(3):356-360

Zhang P (2017) Diversity of Macrofungi in the Greater and Lesser Khinggan Mountains. Jilin Agricultural University, Changchun

Zhang RZ (1965) Pinus camphorae planted on the arid sunny slopes of Daxing 'anling has a preliminary effect. Pract For Technol $13: 11$ 
Zhao HX, Wang YH, Li JQ, He XL (1987) Age structure, horizontal pattern and management of Natural Larch Forest in Tahe Forestry Bureau. J Northeast For Univ 15:60-64

Zhou YL (1991) Vegetation of Daxinganling in China. Science Press

Zhou YL (1994) Vegetation of Xiaoxinganling in China. Science Press

Zhou YL (1997) Vegetation geography of Northeastern China. Science Press, Beijing

Zhou YL, Zhao G (1964) The type, distribution and succession of natural secondary forest in Changbai Mountain forest area-Xiaoxinganling Mountains. J Northeast For Inst 3:33-44

Zhou RC, Zhou YL (1985) Plant resources of Heilongjiang province. Territory Nat Resour Study 4:19-28

Zhou YL, Li JW (1964) The characteristics and distribution of the main vegetation types in the eastern mountainous areas of Northeast China. Chin J Plant Ecol 2(2):190-205
Zhou YL, Wu HQ, Chen T, Zheng YR (1989) Accelerating the recovery of forest in the Burned Area in Daxing'anling according to the synecological characteristics. J Northeast For Univ 17(8):2-9

Zhou YL, Ni HW, Zhou RC (1998) Characteristics of forest plant diversity in Daxing'an Mountains. Territory Nat Resour Study 3(16):66-68

Publisher's Note Springer Nature remains neutral with regard to jurisdictional claims in published maps and institutional affiliations. 